\title{
Medidas tipográficas: un recuento
}

\author{
Typographic measures: a recount
}

\author{
Oriol Moret Viñals
}

Tipometría, Imprenta, Breve repaso al desarrollo de la concepción métrica en la tipografía en plomo, Medidas, Historia de la tipografía, Medidas tipográficas tradicionales alternativa y complemento de la visión habitual en lo que conocemos como "tipometría". Se parte de una noción amplia de medida: el factor cuantitativo se dilata con la articulación de relaciones proporcionales e integra la dimensión cualitativa de los sistemas métricos tradicionales. La tipografía se considera bajo presupuestos similares: como sistema articulado de piezas materiales cuyas magnitudes contienen usos y valores específicos, más allá de su simple expresión numérica. Con tales premisas, se revisan fuentes documentales significativas del "período de la imprenta manual". Su examen, vinculado a los usos y costumbres de oficio, desvela la distinta aproximación métrica, que puede resumirse en tres fases evolutivas: hermética, intensiva, expansiva -como recogen las referencias de los cuerpos tipográficos: adjetivas, sustantivas, numéricas. Se proporciona así un marco para apreciar el cambio de sentido en las medidas tipográficas hasta nuestros días.

\footnotetext{
"Typometry"

(Type measurement), Letterpress Printing, Measures, History of Typography, Traditional Type Measures
}

\begin{abstract}
Concise survey on the development of the metrical conception in letterpress typography, as an alternative and complement to the usual view in the so-called "typometry" (type measurement). Measure is taken here in a broad sense: the quantitative element expands through the articulation of proportional relationships to include the qualitative side of traditional systems of measurement. Letterpress typography is likewise considered: as an articulated system of material pieces whose magnitudes contain specific uses and values, far beyond their sole expression as numeric quantities. Such premises serve to review key sources from the "letterpress period". The examination considers usage and customs of the trade and reveals different metrical approaches that can be summarized in three evolution stages: hermetic, intensive, expansive-as implied in type bodies references: adjective, substantive, numeric. A framework is thus set to appreciate the change of significance that typographic measures have gone through up to this day.
\end{abstract}

\section{Apunte preliminar}

En este artículo, ni "métrico" ni "sistema métrico" remiten al "sistema métrico decimal"-aquel que, dispuesto a fines del siglo XviII, tuvo repercusión internacional hasta ser de uso común en nuestros días. 
No: éste es "tan sólo" un sistema métrico de entre los posibles y así se lo distingue en el texto, como "sistema métrico decimal", propuesta singular a pesar de otros sistemas métricos decimales. Por "métrico" cabe entender aquí "de medida", "relativo a la medida" —en sentido amplio, sin adscripción concreta a ningún sistema, base, unidad o tradición; tan amplio como el mismo concepto de medida.

\section{Medida}

Cualquier repaso histórico a las medidas tipográficas debe considerar su origen en las medidas tradicionales -aunque se limite a las de longitud ${ }^{1}$. Bastará lo acostumbrado: distintas áreas y culturas usaban las mismas medidas. Éstas, genéricas, tenían distintas magnitudes reales en distintos lugares y tiempos; complicaban conversiones, originaban disputas - pero su fondo conceptual resistía.

Todo sistema métrico se fundamenta en el principio de una base numérica, que indica los agrupamientos de cosas o cantidades. Sin embargo, este sistema puede combinar distintas bases en su seno, sean bases complementarias, o múltiplos y submúltiplos. La combinación de bases le aporta riqueza factorial: así, se acepta que los sistemas de medida "tradicionales" o "antiguos" (anteriores a la implantación del sistema métrico decimal del siglo XVIII) eran predominantemente de raíz duodecimal (base 12), pero este predominio no supone exclusividad - una "medida duodecimal" podía ser divisible en "base" 8; por esto mismo, 24 puntos tipográficos pueden ser tanto $8 \times 3$, como $12 \times 2$, como $6 \times 4$.

Es más, contra la noción de un sistema métrico uniforme para medir todas las cosas, se diría que, en el entorno tradicional, conviven diversos sistemas métricos específicos para cada grupo de cosas que éstos serían subsistemas de un sistema métrico genérico. Así, se reformula el orden numérico en términos prácticos, más allá de los puramente aditivos, o de acumulación de unidades: las bases numéricas (módulos, submódulos, supramódulos) introducen nuevas escalas en el sistema; con las escalas, se recalifica la cantidad, se matiza el grado.

A menudo, los sistemas de medida tradicionales se dicen "cualitativos" - para acentuar que, en la práctica de medir, no sólo interviene el factor cuantitativo: el uso de las medidas implica un vínculo emocional "significativo". Esta dimensión significativa se aprecia con mayor intensidad en las medidas "antropológicas". En general, se entiende el "sistema antropométrico" como el conjunto articulado de medidas que toman como referencia las partes del cuerpo humano. Estas partes son articuladas, dinámicas. Por esto, las denominaciones de las medidas antropológicas indican el ámbito y el nivel de relación del hombre con el objeto a medir. Esta indicación no es siempre directa, ni clara (¿qué tiene que ver, realmente, la pulgada con el pie?). La extrañeza desaparece cuando la medida antropológica 
originaria se reformula en patrón — cuando se hace convencional, pierde parte de su significación, y se normaliza en términos cuantitativos (de "mi codo" a "el codo"). Desde esta normalización cuantitativa, cualquier magnitud es comparable a cualquier otra por más raras que parezcan las equivalencias. Cuando las magnitudes se entienden como intervalos entre dos puntos, siempre se podrán establecer concordancias, próximas o lejanas ${ }^{2}$.

La Tabla 1 quiere ilustrar lo anterior: agrupa las relaciones cuantitativas usuales entre las medidas de longitud tradicionales según su nivel "significativo", reconsiderado en términos íntimamente físicos -pasear, abrazar, manejar, pellizcar. (Figuras 1, 2 y 3)


Figuras 1, 2, y 3 Los tres niveles básicos de proximidad e intimidad métrica en la tipografía: se abrazan las formas, se manejan los moldes, se pellizcan los tipos (LEFEVRE, 1855, p. 19, 6, 5.) 


\begin{tabular}{|c|c|c|c|c|c|c|c|c|c|c|c|c|}
\hline & & \multicolumn{2}{|l|}{ paseo } & \multicolumn{3}{|c|}{ abrazo } & \multicolumn{2}{|c|}{ manejo } & \multicolumn{4}{|l|}{ pellizco } \\
\hline & & cana & paso & codo & pie & palmo & palma & Cuarto & pulgada & dedo & línea & punto \\
\hline \multirow{2}{*}{ paseo } & cana & 1 & $1 / 2$ & $1 / 4$ & $1 / 6$ & $1 / 8$ & $1 / 24$ & $1 / 32$ & $1 / 72$ & $1 / 96$ & $1 / 864$ & $1 / 10368$ \\
\hline & paso & 2 & 1 & $1 / 2$ & $1 / 3$ & $1 / 4$ & $1 / 12$ & $1 / 16$ & $1 / 36$ & $1 / 48$ & $1 / 432$ & $1 / 5184$ \\
\hline \multirow{3}{*}{ abrazo } & codo & 4 & 2 & 1 & $2 / 3$ & $1 / 2$ & $1 / 6$ & $1 / 8$ & $1 / 18$ & $1 / 24$ & $1 / 216$ & $1 / 2592$ \\
\hline & pie & 6 & 3 & $11 / 2$ & 1 & $3 / 4$ & $1 / 4$ & $3 / 16$ & $1 / 12$ & $1 / 16$ & $1 / 144$ & $1 / 1728$ \\
\hline & palmo & 8 & 4 & 2 & $11 / 3$ & 1 & $1 / 3$ & $1 / 4$ & $1 / 9$ & $1 / 12$ & $1 / 108$ & $1 / 1296$ \\
\hline \multirow{2}{*}{ manejo } & palma & 24 & 12 & 6 & 4 & 3 & 1 & $3 / 4$ & $1 / 3$ & $1 / 4$ & $1 / 36$ & $1 / 432$ \\
\hline & cuarto & 32 & 16 & 8 & $51 / 3$ & 4 & $11 / 3$ & 1 & $4 / 9$ & $1 / 3$ & $1 / 27$ & $1 / 324$ \\
\hline \multirow{4}{*}{ pellizco } & pulgada & 72 & 36 & 18 & 12 & 9 & 3 & $21 / 4$ & 1 & $3 / 4$ & $1 / 12$ & $1 / 144$ \\
\hline & dedo & 96 & 48 & 24 & 16 & 12 & 4 & 3 & $11 / 3$ & 1 & $1 / 9$ & $1 / 108$ \\
\hline & línea & 864 & 432 & 216 & 144 & 108 & 36 & 27 & 12 & 9 & 1 & $1 / 12$ \\
\hline & punto & 10368 & 5184 & 2592 & 1728 & 1296 & 432 & 324 & 144 & 108 & 12 & 1 \\
\hline
\end{tabular}

Tabla 1 Uso, articulación y relaciones de las medidas básicas de longitud tradicionales. La tabla presenta las unidades catalanas, pero el esquema general es común a la mayor parte de culturas. Se toma el valor más aceptado del punto, 1/12 de línea -el punto tipográfico es de 1/6 de línea. Según las fuentes de conversión, el pie oscilaba entre 260 y $325 \mathrm{~mm}$

\section{Tipografía}

Tipografía es escritura con moldes. La técnica tipográfica invierte profundamente los principios de la escritura manual, en términos productivos y conceptuales, por su condición física: las letras son piezas 3 .

La letra tipográfica se fabrica, y esto comporta usar los recursos de todo oficio que produzca objetos: el instrumental productivo se calibra según patrones métricos comunes a un área geográfica. Ahora la letra mide, ocupa, tiene volumen y pesa - y se puede comprar y vender. Con eso, parece "más medible" que cualquier otra.

A pesar de ello, el estudio de medidas tipográficas ("tipometría") ha priorizado la magnitud longitudinal del cuerpo -aquella en que quedaba encapsulada la letra y que no se percibía en la letra impresa ${ }^{4}$. Las otras magnitudes - alturas tipográficas, pesos y cantidades de las fundiciones, precios...- han recibido un interés residual: en estas páginas tampoco figurarán, pero conviene apuntarlas para acentuar la noción de medida que se maneja aquí.

Igualmente, se cree que las piezas tipográficas contienen usos y valores - con sus cambios a lo largo de los tiempos y a lo ancho de los lugares. Que, aunque no se perciban en las piezas, sí se intuyen en las palabras: medida (ancho de caja), justificar (igualar las líneas a la medida), grado (cuerpo), póliza (lista de cantidades de caracteres a fundir o a emplanar) o distribuir (restituir los tipos a sus cajetines tras imprimir el molde) evocan un universo métrico nada casual. 


\section{La tipografía como sistema}

El requisito fundamental de la composición tipográfica es que el molde a imprimir esté justificado; que todas sus líneas se ajusten a la misma medida lateral; que, con independencia de los tipos movibles, formas gráficas o cuerpos que se usen, el molde final sea sólido. Esto hizo inventar los blancos tipográficos - las piezas que, de menor altura que los caracteres impresores, espaciaban y completaban las líneas sin dejar huella. En rigor, la tipografía se fundamenta en los blancos y es a través de ellos donde mejor se advierte su condición de sistema modular, como conjunto relacionado de piezas proporcionales.

El módulo tipográfico por excelencia es el cuadratín (o eme, también línea), la pieza de sección cuadrada, de grueso igual al cuerpo -así, cada cuerpo tiene su cuadratín, el cuadratín es una medida relativa: su "desorientación" o polivalencia apunta al desarrollo en superficie característico de la técnica, a lo largo y ancho.

El cuadratín (el cuerpo en abstracto) proporciona "su" serie de blancos tipográficos por multiplicación y subdivisión, en supramódulos y submódulos, reflejo de su origen duodecimal: entre los primeros figuran los cuadrados (de $11 / 2,2,3$ y 4 cuadratines) ${ }^{5}$; entre los segundos, el medio cuadratín y los espacios, grueso $(1 / 3 \mathrm{de}$ cuadratín), mediano $(1 / 4)$, fino $\left(1 / 5 \mathrm{O}^{1 / 6}\right)$ y de pelo (supuestamente $1 / 12)^{6}$. (figura 4 )



Figura 4 Los blancos tipográficos en la Encyclopédie: piezas características de la nueva técnica, la fundamentan como sistema proporcional

La lectura numérica de proporciones subraya el papel referencial del cuadratín: los cuadrados son de tantos cuadratines, los espacios son de tantas fracciones del cuadratín. Pero si encima se leen las palabras - los nombres de las piezas-, las proporciones numéricas adquieren el sentido implícito de su uso ${ }^{7}$. Los cuadrados sirven para completar la línea a final de párrafo y rellenar áreas grandes como imposiciones, birlíes y planas en blanco: son, entonces, piezas para cuadrar el molde en un sentido específico de encajar, ajustar, justificar. Los espacios, en contraste, "sirven para dividir las dicciones", y sus 
distintos gruesos permiten "proporcionar los claros" (SIGÜENZA, 1822, p. 267): los espacios abren, aclaran proporcionalmente la composición de la línea. Entre estos extremos, el cuadratín despliega un uso de compromiso: sangrar las líneas. Actúa pues de bisagra, y nexo, de las dos clases de espacio -entre el microespacio intertextual de los espacios tipográficos, y el macroespacio paratextual de los cuadrados; o, tal vez mejor, entre el espacio expansivo, de apertura, y el espacio compresor, de cierre. Luego el espacio del cuadratín es relativamente neutro, ni pequeño ni grande, ni de apertura ni de cierre. Su neutralidad lo reafirma como módulo constructivo, generador de relaciones espaciales.

En resumen, los blancos tipográficos se desdoblan en tres subconjuntos porque el espacio de composición tipográfica se resuelve a tres niveles básicos. Las piezas más características de la escritura tipográfica, los vacíos sólidos, recogen y fundamentan el sentido de sistema proporcional interno ${ }^{8}$.

Esto quiere decir que la tipografía es sistemática por definición; que todo alfabeto tipográfico (o fundición particular: un conjunto de formas gráficas encapsuladas en un cuerpo cualquiera) obedece a criterios internos de proporción. Cosa distinta es que el patrón métrico concreto que se haya adoptado para producirlo sea de aplicación generalizada en un territorio extenso: desde ahí, la métrica tipográfica sigue el curso habitual de todo oficio, con orígenes locales y evolución internacional.

\section{La medida reservada: de los incunables a Plantin}

En sus inicios, la imprenta se arropa en cierto secreto (como "arte negra” de artificio y engaño) e intimidad (un solo obrador podía conjuntar las distintas especialidades del oficio tipográfico). Desde bien temprano aparecerían fisuras en este marco (con los impresores itinerantes, por ejemplo), pero el momento continuaba marcado por la proximidad y el localismo.

Esta situación aconseja considerar criterios métricos distintos a los habituales y recuperar la dimensión cualitativa de las medidas tradicionales: en la letra tipográfica, la medida sería una cualidad difícil de extraer, sin valor autónomo, adjetiva. La concepción métrica de la tipografía en este tiempo sería hermética.

Aunque el elemento métrico sea necesario e ineludible en las letras de la nueva escritura, no se explicita más que en casos singulares -fuera del obrador, en las hojas de muestra (reclamo) y en los documentos legales (recolección). 


\section{Muestras}

Bastarán tres ejemplos: la lista de libros de Peter Schoeffer (hacia 1467), el Indicis de Ratdolt (1486) y el inventario-herencia de Pere Posa (1507).

Al pie de la lista de Schoeffer aparece la enigmática muestra de tipos "hec est littera psalterij", "ésta es la letra del salterio". (Figura 5) La expresión indica dónde se usó la letra en cuestión (ésta, sólo ésta, es la letra de aquel Salterio que Schoeffer y Fust publicaron en 1457) y enlaza magnitud, forma y uso (o destino, o producto bibliográfico). A la vez, insinúa una designación nominal semejante a las que pronto estilarán los grados tipográficos.

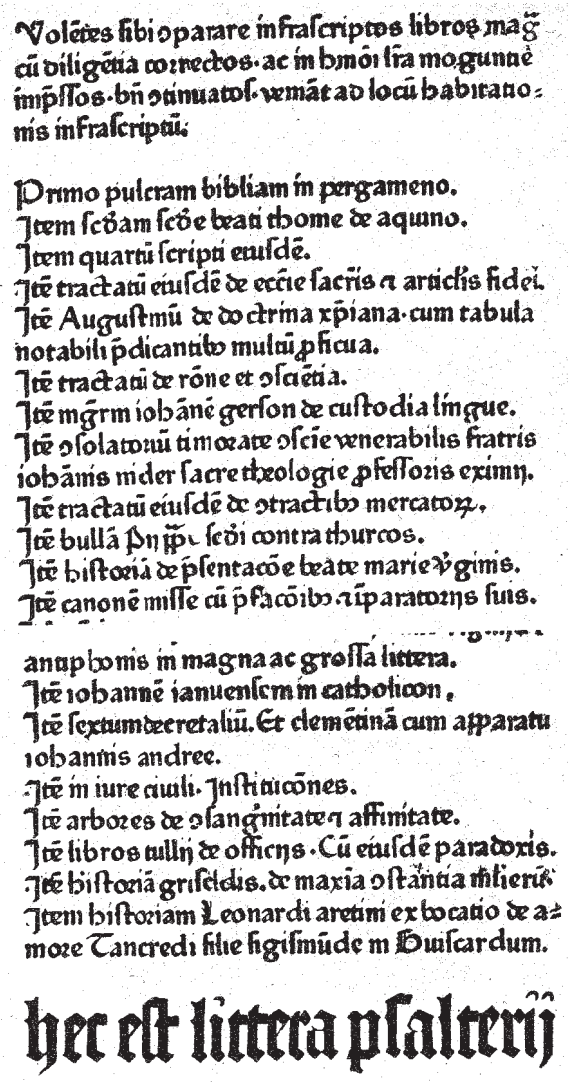

Figura 5 Hec est littera psalterij: la lista de Schoeffer (ca. 1467) [STEINBERG, 1955, p.2]

Líneas atrás en la misma lista figuraba la entrada "antiphonis in magna ac grossa littera”. Aquí, la letra no se sustantiva como en el caso del Salterio: aparece como cualidad del sujeto-libro cuya magnitud tácita se recalca. "Magna ac grossa" ("grande y gruesa") adjetivan la letra de este antifonario en largo y ancho - lo que significa que la letra "de antifonario" puede ser de otros modos. En el fondo, se está reconociendo la condición genérica de libro y letra: la letra tipográfica no es de ningún libro, y difícilmente de nadie o de nada. 
En contraste, el Indicis de Ratdolt (figura 6) presenta, en dos columnas, catorce párrafos en distintos tipos de letra: diez de gótica rotunda, tres de romana, una de griego. Las muestras se ordenan por grupos formales y, dentro de cada grupo, por la magnitud (cuerpo), de mayor a menor.

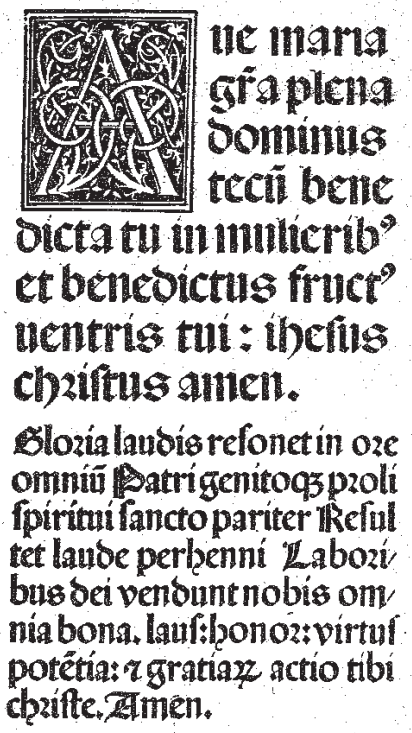

Zine beüfic r vittesperfeculacin Cta. Prouibet z tribunt sensolunia nobis. Ra zoficitabróne seo null' in osbe habo2. Zylla placet tellp in qua reg parua beatū. Dse facit a tenueg ituririantur opes.

Sifozanna volet fies berlictoreconfitl. Si volet beces oem fices secöfitlerbcto?

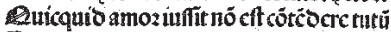
Regnat er in bominos ins habct ille finos

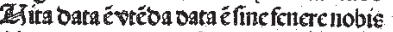
Dutua:ncecerta perfoluenos oic.



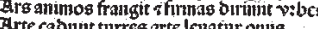
Arte cabunt turreses artelecuatur onus

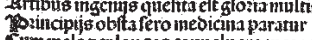



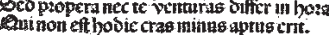

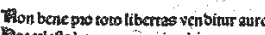



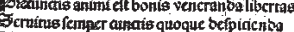

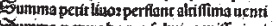



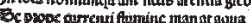



Elt homini uirtus fuluo preciofiot auro: renzas Ingcniun qquondam fucrac preciofius auro. Miranurq gnagis quos muncra mentis adomate Quam qui corporels cmicuere bohis Ex alia quadan forfitan ipic niter

Nomo fuc budisnimium lcttrur bonore Ne vilhs factus polt titua fata genat. . Ncmo nimis cupidetibi res defideratullas


Sicd is fint fidci icclipice quid moncant

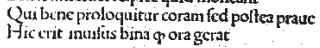



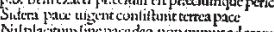

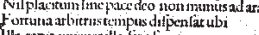

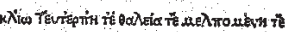

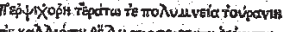

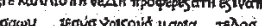

Juoicis characte su sueriaz mane, nicru impzeffoni paratarti: finis.

Erbaroi Rarbolt Anguftenfis viri folcrillimitpreclaro ingento t mivi ficaste:qua olini Dentrijgercellut celebsatifimuns. In imperialinunc vrbe Angutte vinbelicor laviogtin ine imprchion sedit plnnogs

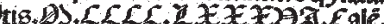
: 7 pilis Dioere felici compleuit.

Figura 6 El índice de caracteres anónimos de Ratdolt (1486) [STEINBERG, 1955, p.3]

Los caracteres trastocan aquella enumeración lineal de Schoeffer para exhibir su comportamiento en áreas de texto. Sin embargo, su referencia queda supeditada a la condición que ostenta el título de la hoja: un índice, que los registra en cierto orden y los muestra (indicare), sin más datos -los caracteres no tienen valor intrínseco explícito, no se les reconoce ninguna singularidad que permita su identificación. 
Esta cualidad anónima, "impersonal”, es consecuente tanto con la raíz técnica de la tipografía como con la finalidad y la noción de muestra de tipos planteada como índice. Una muestra-índice presenta caracteres a un destinatario (editor, autor,...) para que éste elija, distinga aquél que le convenga. Y la forma más básica de elegir en un índice es indicar, señalar ("quiero ésta"), tal como, en otro plano, se presentaba la letra del Salterio de Schoeffer. Pero, mientras ésta se indicaba en términos singulares de autoridad (prestigio, status), esto es, se indicaba a sí misma, las de Ratdolt esperan ser indicadas, singularizadas.

Semejante mutismo enlazaría con aquel carácter "hermético", reformulado: no es necesario nombrar aquello que se muestra y menos cuando esta exposición se circunscribe a un entorno próximo, cerrado, que permite la distinción efectiva, in situ, sin tener que recurrir a la palabra.

\section{Documentos legales}

Algo parecido ocurre en el inventario-herencia de Posa:

2. Item vuyt caxons de fusta ab diverses casses, fornit de letres de stampa, ço és, letra groça, e letra mitjana, e letra de glosar, e letra manuda9.

La correspondencia concreta entre el registro y la pieza física (uno-a-uno) hace innecesaria una terminología más ajustada: al ver las piezas se determinará cuál es cuál. Pero lo significativo aquí es que el criterio de identificación es métrico. Los calificativos groça, mitjana, manuda dibujan un esquema básico y, así, esencial, de relación métrica. Desde una visión cuantitativa, las denominaciones se tildarán de groseras, pero son tan justas como las medidas referidas: con cuatro "grados" se abarca el espectro de producción tipográfica; el conjunto de las cuatro letres constituye el equipo de supervivencia tipográfica, su suficiencia.

Bajo esta concepción, los calificativos remiten a franjas de uso. Y, cuando se precisen estos usos, surgirán franjas subsidiarias, o intermedias, que se nombrarán, como letra de glosar -donde la referencia métrica no es explícita, pero se adivina por asociación: entre la mitjana y la manuda, por debajo de las que se pueden glosar en los libros. "De glosar" (o luego glosilla) amplía el universo métrico básico y cotidiano, que quedaba recogido en groça, mitjana y manuda ${ }^{10}$.

Al cabo del tiempo, se replantearán los términos comparativos, o de proporción, por considerarse insuficientes (excepto cuando califiquen nuevas denominaciones, como lectura chica); a su lado, las "nuevas" medidas se especificarán con una terminología métrica propia, derivada de los usos bibliográficos. 


\section{La medida nombrada: de Plantin al Romain du Roi}

En los siglos XVI-XVII se consolidan los nombres de los grados tipográficos, se reconoce la especificidad de las medidas tipográficas: nombre y medida se enlazan en el cuerpo del grado tipográfico. Los grados pueden ser todavía adjetivaciones métricas de "la letra", pero es sintomático que ahora las medidas se sustantiven en ellos: los grados se distinguen mediante nombres propios.

La especificidad se concreta tras entender el conjunto tipográfico como eso mismo, como un conjunto, un espacio propio donde los grados establecen relaciones entre sí. Si esto ya se intuía antes, ahora conviene que se explicite, por varias razones encadenadas. Entre ellas, el distanciamiento físico de las funciones y de los oficios tipográficos supone una cierta apertura del hermetismo anterior -y se acusará con los tratados de imprenta, a fines del siglo XVII. A su vez, el número de grados tipográficos aumenta, lo cual obliga a desarrollar recursos de registro y control que señalen sus características métricas.

Puntualícese el incremento: el conjunto tipográfico continúa siendo un espacio cerrado, definido por unos límites, que sólo se pueden "abrir" en su interior. Tal apertura no es una expansión, sino un crecimiento interno. La concepción métrica de la tipografía cambia de hermética a intensiva.

\section{Plantin}

En 1567, Plantin saca a luz su Index sive specimen characterum, una muestra de caracteres en dieciséis páginas que compuso para atraer la financiación real de "su" Biblia políglota. Esto debió condicionar el cuidado en la presentación y su organización: los grupos alfabéticosformales se suceden en orden inverso al común (hebreo, griego, latín redondo, latín cursivo, gótico, civilité). Dentro de los grupos, los grados tipográficos continúan sucediéndose en orden decreciente, sin ningún dato propio. Únicamente se identifican los textos de muestra con un título, como de fórmula híbrida entre la de Schoeffer y la de Ratdolt: sin la carga concreta de "ésta es..." en la primera, ni la necesidad de señalar en la segunda, aquí se puede indicar un carácter con una expresión parecida a "aquél con que se compuso el fragmento de De Oratore”. (figura 7) El carácter sólo se puede referir mediante la identificación del pasaje textual, a modo de "pre-nominación" indirecta que puede convertirse en nombre o rasgo identificativo como "la letra del Salterio", pero sin usarse para el Salterio más que en simulación. Curiosamente, tal simulación resulta necesaria para dar el paso hacia la designación genérica de grados tipográficos: la sistematización en el Index de Plantin deja atrás las muestras de "letras como éstas" e insinúa el camino hacia una "nueva" definición de los caracteres. 


$$
\text { 11. } 01110 .
$$

N 8 s 1 eft tam inbumanum, quim doguentiam z naturz ad falutem \& conferuationem dacam, ad bonorum peftem, perniciem que conuerte2t. 2. Ofir.

Nihil elteam incredibile, quod non dicendo fiat probabile. Nihil tem horridum, tam incultum, 'quod non fplendefcat oratione, \& tanquam excolatur. Paradox.

Eloquens hoc vel maxime differt à diferto". Difertus eft enim, qui poreft fatis acute atque dilucide, apud mediocres homines, \& communi quadam hominum opinione dicere. Eloquens verò, qui mirabilius \& magnificentius augere poteft; itque ornare qux vulicomnesqú omnium rerum, qua ad dicendum pertinent, fontes animo ac memoria continet. 1. de Orat.

\section{T. DI OnATOAx}

No I $_{1}$ I materis of docti, omandes eft, qui fcelm fraudemg que nocentis pofit dicendo fubiicere odio cinium, s uppliciogúe constring are, sdemgúe mgenï prefidio unnocentinan indiciorum pana liberare: idemgúe longuentem labenteng úe populum, aut ad decus excitare aut ab errorededucte, ane inflammare in umprobos, aut incitatum in bon os mitigare : gui desigue quemensque in anmes bominum motum res of cassa posfulet, eum dicendo vel excitare posit, vel sedare.

Zeno Rhetoricam palme, Dialecticam pugno fimilem effo dicebar: quòd Latius loguerentur R hetores, Dialecticis antem compresisss. 2. de Finib.

Quo quifque oft folertior of ingeniofior, boc docet inacum-

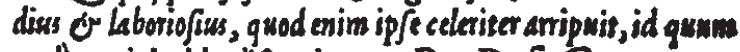
sarde percipi videt difcruciatur. Pro Rolc. Com.

Quo vis verfutior of callidior, hac inujfor on suppetior, detratia opinione probitasis. 2.Offic.

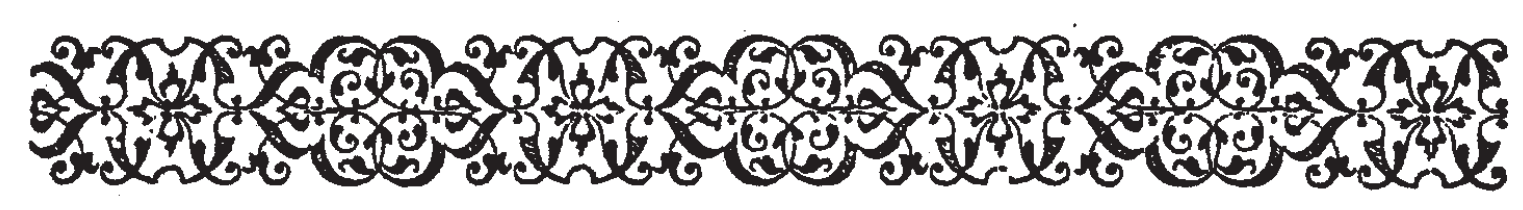

Figura 7 La indicación simulada de Plantin: el texto del catálogo puede terminar por bautizar al alfabeto tipográfico “a la manera de" la letra del Salterio de Schoeffer [DREYFUs, 1972, n. 16.]

Plantin mismo cambia y precisa los términos en sus inventarios, entre los que sobresale el apodado Folio Specimen (1585?), al parecer compuesto para vender matrices. Lo más evidente es que los caracteres se nombran. (Figura 8) En este nombrar caben los motivos productivos y comerciales -de registro y organización internos, y de referencia para transacciones externas. Las muestras incorporan tales criterios porque ahora el juego o serie de material tipográfico se ha fragmentado, se ha dispersado físicamente, por lo que se cree necesario usar indicadores de identificación inequívoca de las piezas originales que ya no se tienen. 


\section{Afendonica Romaine.}

Alfonfus rex Arrag. Idem dicerefolet, ita demùm matrimonium tranquillè citraquue querimonias exigi poffe, fi maritus furdus fiat, vxor cæca: innuens, opinor, foemineum genus obnoxium effe zelotypix, atque hinc ariri rixas \& querimonias: rurfum maritis permoleftam effe vxorum garrulitatẽ : qua moleftia cariturus fit , fi fat furdus: nec illa vexabitur adulterij fufpicione, fir careat oculis.

Valeria Meffalarum foror, rogata, cur amiffo Seruio viro, nulli vellet nubere: Quoniam, inquit, mihi femper viuit maritus Seruius.

\section{Parangonne fur $P$ Afcendonica.}

Narratur \& illud Catonis dictum, fi fine vxoribus mundus effe poffit, vita noftra non effet abfque dijs. Senfit feliciffimam hominum vitam fore, fi datum effet à coniugio liberos viuere. Sed vt idem ait apud A. Gellium, cum illis incommodè viuitur, fed fine illis omnino non viuitur, vt meritò dici poffit, vxor neceffarium malum.

Afcendonica Curfune.

Anaxagoras Claz. Poft diutinam peregrinationem domesm reuer fus reperit $p a-$ triam poffefsiones ǵs fras de ertas: $N_{i j} f$, inquit, iffa periffent, ego faluus non effem: Quid calamitas illum adegifet ad philofophiam: Rebus autem integris, manfafet intra penates fuos. Fta japessumerò prospera funt homini, que roidentur aduer $\int a$ : Equod damnum putatur ingens, lucrum ef maximum.

Figura 8 El Folio Specimen: la ordenación decreciente, o intensiva, de los cuerpos tipográficos se mantiene con cierta comodidad en la relación de formas intermedias, habituales en Plantin -Parangonne sur l'Ascendonica ("romain") se encuentra entre Ascendonica Romain y Ascendonica Cursive. (DREYFUs, 1972, p. 17) 
El criterio de ordenación es el más funcional, cotidiano, de oficio: la medida. Los caracteres se suceden de mayor a menor sin atender a su forma gráfica u origen lingüístico, los grupos formales se "mezclan" bajo la medida. La métrica se antepone a la forma, o bien, la medida del grado tipográfico conjunta las distintas formas - y conviene remarcar que se trata de "la medida del grado tipográfico", no propiamente del "grado tipográfico": las muestras del Folio Specimen certifican que la relación entre grado y medida, o cuerpo y ojo, no es en absoluto cerrada y que se puede abrir, que una misma forma puede incorporarse en distintos grados, que de un mismo juego de punzones (y de matrices) se pueden obtener tipos movibles de distinto grado. Esta ruptura, al fin, se evidencia cuando se denomina -y la denominación se califica en términos métricos: Parangonne sur la Reale, por ejemplo.

\section{El espacio cerrado de los grados tipográficos}

Los tipos movibles no tienen sentido por sí solos. Empiezan a tener sentido cuando se imprimen en un soporte. El soporte ideal para la tipografía es el papel, que se origina en un molde, la forma papelera. El espacio idóneo de confluencia de los ámbitos papelero y tipográfico es el libro, donde conviven sus módulos operativos: el pliego y el grado tipográfico. En rigor, el "formato" de un libro siempre es submódulo, parcela regular del módulo-base delimitado por la forma - folio, $4^{\underline{0}}$, 8 o... son magnitudes relativas que remiten al número de dobleces aplicados a la hoja. La unidad inicial, máxima, limitada físicamente, genera el resto de unidades por división sucesiva. Esto explica que los grados tipográficos, al igual que los modelos de imposición y casado en los manuales de imprenta, se enumeren en secuencia "decreciente" -no por simple mimetismo, también por lógica: "a formatos grandes, grados grandes".

En términos métricos, y perceptivos, a cada formato le conviene un grado tipográfico ${ }^{11}$. Pero los nombres de los grados nunca refieren la sola medida del formato - como si tampoco ésta fuera tan significativa. Los tipos movibles cobran pleno sentido cuando se encierran en el marco formado de un género bibliográfico: éste, que califica al formato, sí puede dar nombre a algún grado.

\section{Grados tipográficos: clases, nombres, adjetivos}

Tal como las medidas tradicionales, los grados tipográficos -y sus denominaciones- crecieron y proliferaron según la ocasión, sin designio reglado. Variaban según el lugar, pero se inscribían en un 
esquema conceptual semejante que, hacia la segunda mitad del siglo XVII, estaba ya asentado -con clases más o menos definidas ${ }^{12}$.

Género bibliográfico (o parte). Canon, Misal, Breviario, Filosofía - Bibel, Corpus, Corale, Primer, Pica. (Parangona - Romain.)

Uso bibliográfico. Texto, Lectura, Glosilla - Colonel. (Colineus.)

Obra bibliográfica - autoridad literaria. Atanasia, San Agustín, Cícero - Silvio. Artífice. Garamonde, Gaillarde. (Minion, Colineus.)

Geografía. Parisina, Sédanoise, Parmiginina. (Romain, English, Bourgeoise.) Asociación. Ágata, Perla, Diamante - Robijn. (Jolie.)

Medida. Parangona, Entredós, Miñona, Nomparella - Trimégiste, Palestine (Bourgeoise) - Secunda, Tertia, Mittel, Petit - Ascendiaan, Mediaan, Descendiaan.

Algunos nombres se acompañaban de adjetivos -para señalar grados distintos. Los más usuales remitían a "grande" y "pequeño". Menos frecuentes fueron moyen o vrai, que aparecían redundantes porque calificaban el grado de referencia que no necesitaba atributos. Y, al fin, había los cuantitativos puros como doble ${ }^{13}$.

\begin{tabular}{|c|c|c|c|c|c|c|}
\hline puntos & España & Italia & Francia & Inglaterra & Alemania & Países Bajos \\
\hline 48 & - & Reale & Double Canon & French Canon & Kleine Missal & Parijs Kanon \\
\hline 44 & Grancánon & Corale & Gros Canon & Two-line Double Pica & Grosse Canon & Groote Kanon \\
\hline 36 & Cánon & Canone & Trimegiste & Two-line Great Primer & Kleine Canon & Kanon \\
\hline 28 & Peticano & Sopracanoncino & Petit Canon & Two-line English & Doppel Mittel & Dubbelde Augustijn \\
\hline 24 & - & Canoncino & Palestine & Two-line Pica & Roman & Dubbelde Mediaan \\
\hline 22 & Misal & Ascendonica & Gros Parangon & Double Pica & Text - Secunda & Dubbelde Descendiaan \\
\hline 20 & Parangona & Parangone & Petit Parangon & Paragon & Parangon & Parangon \\
\hline 18 & Texto & Testo & Gros Romain & Great Primer & Tertia & Text \\
\hline 16 & Atanasia & Soprasilvio & Gros Texte & (Large English) & Grosse Mittel & \\
\hline 14 & San Agustín & Silvio & St. Augustin & English & Mittel & Augustijn \\
\hline 12 & Lectura - Cícero & Lettura & Cicéro & Pica & Cicero & Mediaan \\
\hline 11 & (Lectura chica) & (Filosofia) & Philosophie & Small Pica & Brevier & Descendiaan \\
\hline 10 & Entredós & Garamone & Petit Romain & Long Primer & Corpus - Garmond & Garmond - Colineus \\
\hline 9 & Breviario & Garamoncino & Gaillarde & Bourgeois & Borgis & Burgeois - Galjart \\
\hline 8 & (Gallarda) & Testino & Petit Texte & Brevier & Petit - Jungfer & Brevier - Bibel \\
\hline 7 & Glosilla & Mignona & Mignonne & Minion & Colonel & Colonel \\
\hline 6 & Nomparella & Nompariglia & Nonpareille & Nonpareil & Nonpareil & Nonpareille \\
\hline 5 & (Perla - Ágata) & Parmiginina & $\begin{array}{l}\text { Parisienne - Séda- } \\
\text { noise }\end{array}$ & Pearl & Perl & Jolie-Peerl \\
\hline 4 & - & - & Diamant & Diamond & Diamant & Robijn - Diamant \\
\hline
\end{tabular}

Tabela 2 Conversión de los grados tradicionales a puntos tipográficos, adaptada de la que figura en Tormo Freixas (1973). La correspondencia entre grados nominales y valores numéricos no es tan limpia como se indica, pero puede dar cierta idea panorámica de la cuestión: entre paréntesis, los grados dudosos; separados por guiones, los "sinónimos" según qué período; se omiten los menos habituales. 


\section{La articulación métrica del conjunto tipográfico}

La articulación que desplegaron Canon, Parangona y Nomparella puede ilustrar la concepción plurimodular de la tipografía y enlazarla con la variedad o riqueza de los sistemas de medida tradicionales - ya desde sus nombres ${ }^{14}$. Canon es modelo de imitación, máxima autoridad que regula comportamientos debajo suyo. Parangona y Nomparella incorporan la paridad: Parangona, modelo de perfección, es patrón de comparación; Nomparella, sin par, es límite incomparable ${ }^{15}$.

Así, señalan puntos de referencia en el conjunto tipográfico: entre ellos, se desarrollarían aquellas franjas con sus grados de lectura mencionados, de la groça a la mitjana, y de la mitjana a la manuda. Es posible, aunque éstos son criterios mudables en el tiempo, y resulta difícil fijarlos de forma categórica. Más bien, cabría reconsiderar la idea desde los puntos en sí, y no desde las franjas que se extienden entre ellos; estimar su valor utilitario, no en términos de lectura, sino de medida: Canon, Parangona y Nomparella son puntos métricos, patrones de medida cuantificable - supongamos, en proporción 1-2-6 ${ }^{16}$.

Son puntos métricos porque "sirven para medir distintas magnitudes". Pero, en este caso, no son magnitudes de letra, sino de pieza. El conjunto abraza entonces desde el material de imposición (piezas grandes) hasta los espacios tipográficos (piezas menudas); en medio, todo el abanico de los grados tipográficos (piezas medianas). Digamos, pues, que Canon sea patrón métrico para las piezas grandes, Parangona para las medianas, y Nomparella para las menudas. Con esto, la articulación recoge el carácter intensivo de la métrica del período y deviene centrípeta: establece los módulos de acuerdo con unos usos prácticos o con unos niveles de actuación que, en cierto modo, son inclusivos -se abrazan las formas, se manejan los moldes, se pellizcan los tipos. (figuras 9, 10 y 11)
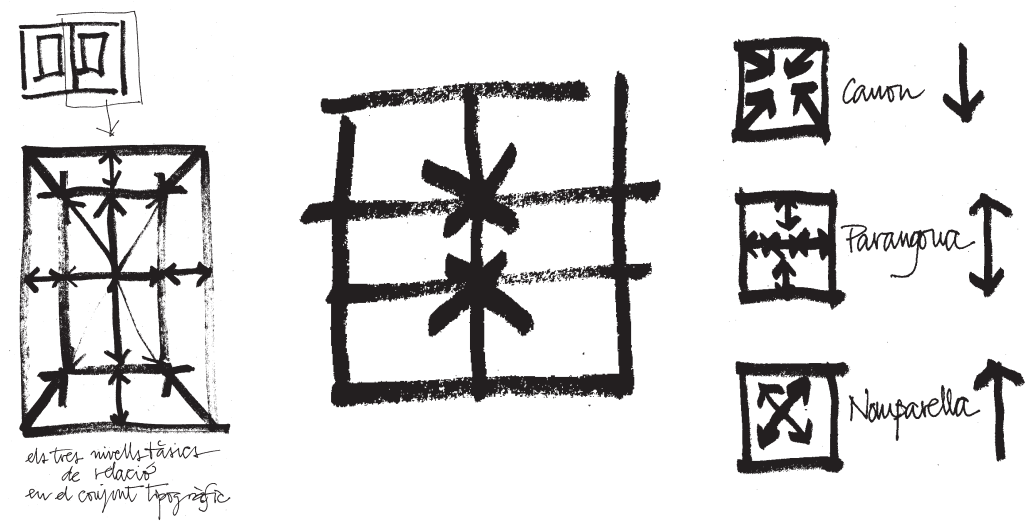

Figuras 9,10 y 11 Los grados tipográficos como niveles de relación en el marco cerrado de la tipografía, y de las magnitudes de letras: Canon y Nomparella, las fronteras; Parangona, la bisagra. 
Recompónganse nombres y usos. Canon y Nomparella, gradoslímite del conjunto tipográfico, desafían todo emparejamiento; sólo los puede emparejar Parangona: en la práctica, no parece haber relación directa entre el material de imposición y los espacios tipográficos, si no es por la "mediación" del molde de grados tipográficos. La articulación intensiva se matiza entonces como proporcionada, conectada, estructurada, donde cada unidad modular cumple un papel, "el suyo", a semejanza de los blancos tipográficos: la menuda es expansiva (los espacios tipográficos aclaran); la grande es oclusiva (las imposiciones cierran la forma); la mediana es conciliadora (determina la medida máxima, el área en que los grados tipográficos se desenvolverán) -Parangona aparece como el patrón métrico más lógico para relacionar, articular, el espacio tipográfico ${ }^{17}$.

Al fin, el paseo por los grados evoca las nociones de cómputo como adición, y de medida como división: las unidades modulares pueden ser tanto la suma de unidades (puntos), como fracciones de una unidad (el pie, por ejemplo) - la magnitud es la misma; la aproximación conceptual, y el procedimiento, no.

\section{La medida numerada: del Romain du Roi a la unificación tipométrica}

La visión "evolucionista" concibe el período de fines del XviI al xx, como último hito de la concepción métrica en la tipografía. Por un curioso e inconsciente sentido de finalidad, la visión no se equivoca: la tipografía de origen terminará por desaparecer del mapa productivo. Talmente curioso, en el traspaso se reafirmará la noción de medida a la que estamos acostumbrados: cuantitativa, numérica, se moldea en los principios de la revolución científica del siglo XVII, se divulga con el espíritu enciclopedista del siglo xviII, se instala en la cotidianeidad pragmática del siglo XIX. Siguiendo el curso, su concepción es expansiva $-\mathrm{y}$ de alcance internacional.

\section{Moxon: la primera cuantificación de los cuerpos tipográficos}

En su Mechanick Exercises (1683-4), el académico Moxon presenta una lista de diez cuerpos tipográficos con su número de cuadratines contenidos en un pie. ${ }^{18}$

Moxon selecciona los cuerpos que considera más relevantes, excluye aquellos en que no percibe diferencia respecto los seleccionados (los holandeses o Small Pica). A grandes rasgos, traza la situación corriente en el entorno local, o el nivel de suficiencia tipográfica del momento. La suficiencia se cifra desde una concepción particular de la diferencia: para Moxon, sólo la diferencia perceptible merece lugar en su lista. Al desestimar las minucias, simplifica el conjunto de grados tipográficos: reduce tanto su número como ajusta sus medidas. 
El ejercicio de Moxon es una muestra de tránsito conceptual, en que resuena la tradición métrica del oficio tipográfico: los cuerpos no son magnitudes aisladas con valor cuantitativo propio, sino cualidades de la letra en tanto que texto potencial; los cuerpos se aprecian mejor desde el conjunto, en relación al conjunto, y, para éste, el pie es el módulo básico, la unidad métrica más apropiada para abrazarlo, para cerrarlo - por ejemplo, en una página de in-folio. En estas condiciones, el pie fundamenta la noción de sistema tipométrico, que relaciona los distintos grados del conjunto tipográfico. O bien, los cuerpos tipográficos aún "no miden nada" - sólo mide el pie, que se subdivide, o contiene, un número determinado de cuerpos.

Esta visión de conjunto se resuelve bajo presupuestos instrumentales de oficio, donde los números se subordinan al factor físico: para exponer las dimensiones de los grados tipográficos con cierta precisión, Moxon traslada y aplica el principio "táctil" de la galga -el instrumento básico en fundición para comprobar las dimensiones de las piezas tipográficas: patrón, contenedor que acoge un número finito de piezas de una magnitud dada. Así, la lista es una galga de cuerpos que mantiene el conjunto tipográfico como un espacio cerrado, limitado.

Pero detrás de su cuantificación numérica se debatía una reordenación de fondo, donde los límites de aquel espacio se habían invertido: la lista de cuerpos empieza ahora por el más pequeño (Pearl) y se cierra con el mayor (Great-Cannon). El detalle es significativo porque insinúa la visión abierta, expansiva, que se irá afianzando en tiempos posteriores: el principio aritmético ordena los cuerpos tipográficos y les infunde mayor abstracción.

\section{Truchet y compañía}

Los dos esquemas métricos que Truchet fabricó para el proyecto del Romain du Roi ${ }^{19}$ entre 1693-5, son de calibre tan imposible que dificultan su resumen. Truchet, ingeniero hidráulico sin tradición tipográfica, abordó su programa tipométrico desde la cuantificación pura, desde cero. (Figuras 12, 13 y 14) 


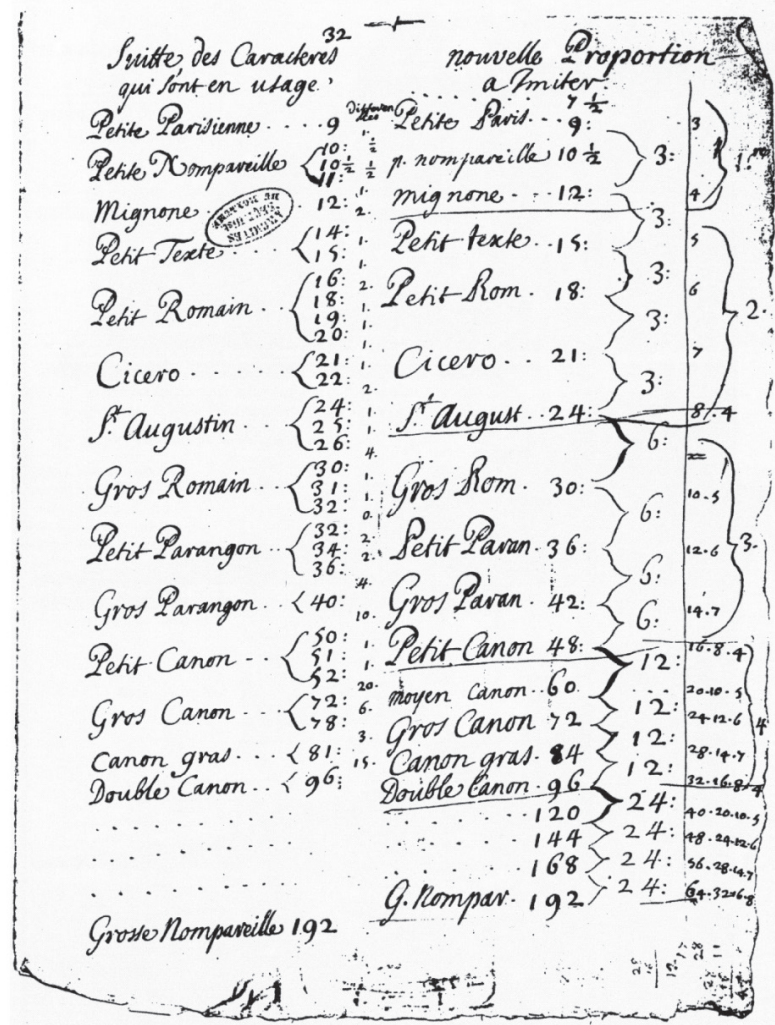

\begin{tabular}{|c|c|c|c|c|c|c|c|c|c|}
\hline \multicolumn{10}{|c|}{  } \\
\hline noms 6 & \multicolumn{4}{|c|}{ 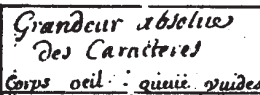 } & \multicolumn{3}{|c|}{  } & & \\
\hline & $7 \cdot \frac{1}{2}$ & $2 \cdot \frac{13}{14}$ & $\begin{array}{c}2 \cdot \frac{7}{64} \\
2 \cdot \frac{13}{72}\end{array}$ & & $\left\{\begin{array}{l}4 \\
5.9 \\
53\end{array}\right.$ & 15: & $\begin{array}{l}12 \cdot \frac{27}{64} \\
14 \cdot \frac{29}{32}\end{array}$ & & \\
\hline & 2. & 1. & $2 \cdot \frac{64}{64}$ & & & $21^{\circ}$ & $\left|\begin{array}{cc}17 \cdot \frac{25}{64} \\
19 \cdot-\frac{7}{8}\end{array}\right|$ & & \\
\hline & 19. & 3: $\frac{5}{8}$ & $4 \cdot \frac{2}{32} \mid$ & $\frac{15}{16}$ & 9. $\frac{28}{32}$ & 30. & $24 \cdot \frac{.2 .}{32}$ & & \\
\hline 800 & 18: & $6 \cdot \frac{3}{4}$ & s. $\frac{1}{16}$ & $1 . \div$ & $11 \cdot \frac{13}{16}$ & 36. & $29 \cdot \frac{13}{42}$ & &  \\
\hline уреике & 21. & $7 \cdot \frac{7}{8}$ & $5 \cdot \frac{20}{3}$ & $1 .+$ & 13: $=31$ & 42 & $34: \frac{2}{2}$ & & तो \\
\hline chasmin & 24. & 9. & $6 \cdot+7$ & $1 . \frac{6}{2}$ & $15 \cdot \frac{7}{4}$ & 48. & 39.2 & & \\
\hline 46 & 30. & $11 \cdot \frac{1}{4}$. & $8-3$ & $1 \cdot \frac{7}{1}$ & $19 \cdot \frac{11}{16}$ & 60. & $49 . \div$ & & $9 \cdot-1$ \\
\hline 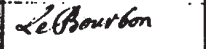 & 36 & $13 \cdot-\frac{1}{2}:$ & $10 \div$ & $2 \cdot \frac{1}{4}$ & $\left|23 .-\frac{1}{3}\right|$ & $>2$. & sy. & $1 . \div$ & $11 \cdot 7$ \\
\hline & 42. & $15 \cdot \frac{3}{4} \mid$ & $11 \cdot \frac{.3}{16}$ & 2. 4 & $27 \cdot \frac{6}{16}$ & $184^{\circ}$ & $69 \cdot \frac{1}{20}$ & $1 \cdot \frac{3}{10}$ & 13. \\
\hline con & 48. & 18. & $\left|13 \div \frac{1}{2}\right|$ & 3 & $31 \cdot \frac{1}{2}$ & $9^{6 .}$ & $79 \cdot \frac{1}{2}$ & $1 \cdot \frac{1}{2}$ & 15. \\
\hline Enor & 60. & $2 \cdot \frac{1}{2}$ & $\cdot \frac{x}{8}$ & $\frac{5}{7}$ & $39 \cdot 3$ & 10. & $\frac{3}{3}$ & $1 \cdot \frac{7}{8}$ & $8 \cdot \frac{2}{4}$ \\
\hline & 72. & 27. & $0 . \frac{1}{4}$ & $4 \cdot \frac{1}{2}$ & $47 \cdot \frac{1}{4}$ & $144^{\circ}$ & & & \\
\hline apeose & 84. & $31 \cdot \frac{1}{2}$ & 23.5 & s. $\frac{1}{4}$ & $\cdot \frac{1}{6}$ & 168. & $\dot{8}$ & & $\frac{1}{4}$ \\
\hline granin ponidustin & $9^{6}$ & 36. & 27. & 6. & 63. & 192. & isg. & & 30. \\
\hline & 120. & 45. & 4 & $7 \cdot \div \frac{1}{2}$ & $y$ & 240. & 27 & & $\frac{1}{2}$ \\
\hline & 144. & ? & $40 \cdot \frac{1}{2}$ & 9. & $4 \cdot \frac{1}{2}$ & 288. & $238 \cdot:$ & $40 \div$ & 45 \\
\hline & 168. & 63 & $47-4$ & $10 \cdot \frac{1}{2}$ & $110 \cdot \frac{1}{7}$ & 336. & & & $32 . \frac{1}{2}$ \\
\hline anello. & 192. & 72. & 54. & 12. & 126. & 384 & & 6 & 601 \\
\hline
\end{tabular}




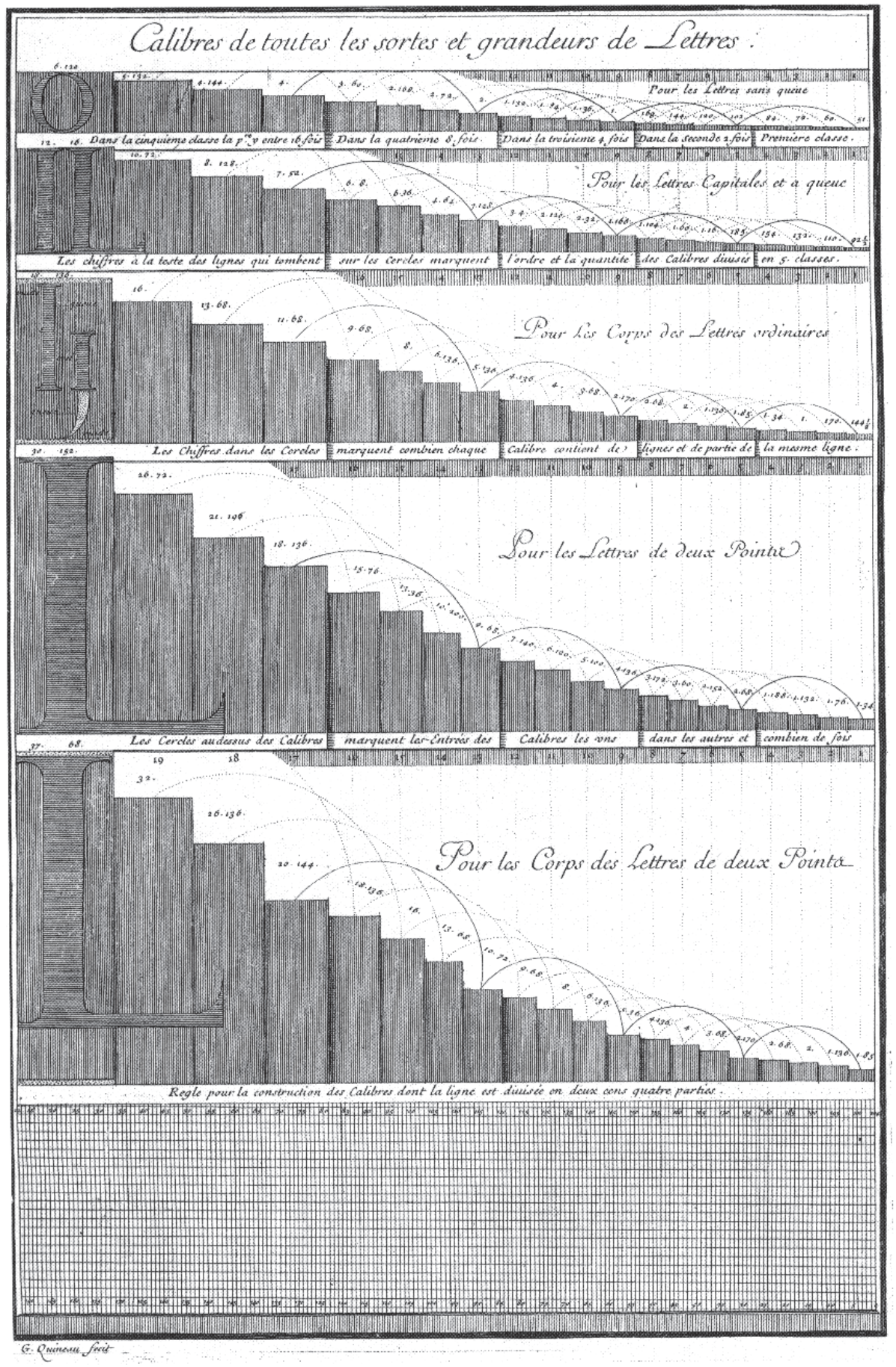

Figura 12,13 y 14 Truchet hace el inventario de cuerpos, registra sus diferencias métricas, los recalibra. Luego, se rebautizarán y se desmenuzarán en su interior. Al final, se reescalará el sistema con finura puntillosa. (MOSLEY, 1997, p. 19; JAMMES, 1961, p. 27; MOSLEY, 1997, p. 20.)

Truchet y compañía tenían que proyectar grados tipográficos para el alfabeto. Cumpliendo el protocolo científico y burocrático, empezaron por medir las letras en uso: seleccionaron las plus belles impres- 
sions, francesas y extranjeras; eligieron el pied de roi como patrón métrico; usaron un bon microscope que registraba lignes secondes de 1/12 de ligne (1/144 de pied de roi) - el valor que acostumbra a asociarse al punto de pulgada ${ }^{20}$. Así, obviaron lo "circunstancial" (midieron muestras impresas, no piezas físicas; e ignoraron las tradiciones métricas particulares de los ejemplares medidos), lo filtraron y redujeron a lo sustancial (la medida oficial) mediante el principio básico de la fracción. Ésta fue una de sus aportaciones fundamentales: al presentar las fracciones secundarias como unidades sustantivas, invirtieron el punto de vista, con lo que el conjunto de grados tipográficos se resolvía como una operación aritmética donde cada uno, "al fin", parecía medir por sí mismo, sin intervención de módulos mayores como el pie.

Truchet enumeró quince grados en orden creciente, registró sus valores numéricos (dando fe así que un mismo grado medía distinto), y las diferencias entre ellos. Tras puntualizar las diferencias, que Moxon desestimaba, Truchet propuso su nouvelle proportion de grados tipográficos, que se articulaba desde los intervalos métricos entre grados, y no desde los grados en sí. Los valores de los nuevos grados no eran las medias de los valores medidos, sino que obedecían a los criterios abstractos del sistema: los cuerpos eran cantidades cifradas - $\mathrm{y}$, al cifrarse, eran convertidos, reducidos al sistema, "degradados".

El conjunto tipográfico se reinventó: los quince cuerpos inventariados crecían a veinte en el nuevo esquema -como integrando la tradición vigesimal. Los veinte cuerpos se distribuían en cinco grupos de cuatro, definidos por un sumando o incremento derivado de la base duodecimal del sistema métrico, según el simple juego de dobles y mitades (11/2, 3, 6, 12, 24 lignes secondes); los cuerpos de cada grupo duplicaban su tamaño en el grupo siguiente, con lo que las franjas de antaño se alineaban ahora en un complejo entramado gobernado por el número.

Luego bautizaron los cuerpos con nuevos nombres: tras asignarles valores que no tenían, los cuerpos dejaban de responder a los antiguos nombres, tanto como los nombres ya no podían contener los cuerpos antiguos. El enlace entre cuerpo y nombre era ahora tan débil que sólo lo sostenía el número: así desmenuzaron los cuerpos en cifras que detallaban las magnitudes longitudinales de pieza y grafismo.

La articulación del sistema, de precisión numérica indiscutible, y su simplicidad operativa de cálculo lo convertían en una opción tipométrica en apariencia superior a la tradicional. Sin embargo, la abstracción de las cifras delataba el desarraigo de la práctica: algunos cuerpos sólo tenían sentido como cifras en el sistema, no como piezas reales.

Truchet y compañía reajustarían las magnitudes en un segundo esquema, con una ligne seconde de $1 / 204$ de ligne. Dicha "unidad" microscópica se alejaba todavía más del oficio y se demostró impracticable en realidad: los cuerpos producidos no pudieron cumplir el refinamiento proyectado - los maravillosos esquemas de Truchet quedaron ideales, ilustrando la nueva concepción de medida. 
De la reacción pragmática a los sistemas tipométricos uniformizadores

De modo gradual, la visión cuantitativa irá impregnando la práctica tipográfica del siglo XVIII. Las tables de Fertel (1723) —cuántas líneas de qué cuerpo entran en páginas de tal o cual formato, etc.- reciben un tratamiento de registro contable ya distinto a las fórmulas discursivas de Paredes (Figura 15). Y las tables y schemes de Smith (1755), con mayor apego a las cifras, se amenizan con muestras reales que certifican las irregularidades de medidas (con la significativa diferencia entre body y size) - para reclamar leyes que terminen con el caos métrico. (Figuras 16 y 17)

\begin{tabular}{|c|c|c|c|c|c|}
\hline \multirow[b]{2}{*}{$\begin{array}{l}\text { Iignes dePe- } \\
\text { titParangou. }\end{array}$} & \multicolumn{5}{|c|}{ Saite de la Table des in-folio. } \\
\hline & $\begin{array}{l}\text { Lig. de Gros } \\
\text { Romain. }\end{array}$ & $\begin{array}{l}\text { Lignes de St. } \\
\text { Auguffin. }\end{array}$ & $\begin{array}{l}\text { Lignes de } \mathrm{C}_{i-} \\
\text { cero. }\end{array}$ & $\begin{array}{l}\text { Lig. de Phi- } \\
\text { loophie. }\end{array}$ & $\begin{array}{l}\text { Iignes.de Pe? } \\
\text { tit Romain. }\end{array}$ \\
\hline $47^{\frac{x}{3}} \ldots$ & 52. & $64 \ldots$ & $73 \frac{x}{2}$ & $78 \frac{x}{2}, \cdots$ & $90 \frac{x}{2}$ \\
\hline $47 \ldots$ & sI $\frac{1}{3} \ldots$ & $63 \frac{1}{3}$ & $72=$ & $77 \frac{1}{2} \cdot$ & $89 \frac{x}{2}$ \\
\hline $46 \ldots$ & so $\frac{x}{4} \ldots$ & $62 \ldots$ & $71 \ldots$ & $76 \therefore$ & $87 \frac{x}{2}$ \\
\hline $45 \ldots$ & $49 \ldots$ & 60 & $69 \cdot \frac{x}{3} \cdots$ & $74 \ldots$ & $85 \frac{x}{3}$ \\
\hline $44 \ldots$ & $4^{8} \ldots \ldots$ & $59 \frac{\pi}{3} \ldots$ & $68 \ldots$ & $72 \frac{2}{3} \cdots$ & $8: 3 \stackrel{x}{ \pm}$ \\
\hline
\end{tabular}

Table poar les pages In-quarto.

\begin{tabular}{|c|c|c|c|c|c|}
\hline $\begin{array}{l}\text { ighess de Pe- } \\
\text { itParangon. }\end{array}$ & $\begin{array}{l}\text { Iig. de Gros } \\
\text { Ramain. }\end{array}$ & $\begin{array}{l}\text { Lignes de St. } \\
\text { Auguaftio. }\end{array}$ & $\underset{\text { cero. }}{\text { Lignes de } \mathrm{Cl} \text { - }}$ & $\begin{array}{l}\text { Iig. de Phi } \\
\text { lolophie. }\end{array}$ & $\begin{array}{l}\text { Lignes de } \mathrm{Pe}^{\text {- }} \\
\text { tit Komaig. }\end{array}$ \\
\hline $3=\frac{\pi}{4} \ldots$ & $34 \ldots$ & $42 \ldots$ & $4^{8} \ldots$ & $S^{1}$ & 59. \\
\hline 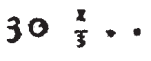 & $33 \ldots$ & $40 \frac{3}{4}$ & $46 \frac{2}{3}$ & $49 \frac{3}{4} \cdot$ & 578 \\
\hline & $31 \frac{3}{4}=$ & & 1 & $47^{2}$ & 55. \\
\hline
\end{tabular}

\begin{tabular}{|c|c|c|c|c|c|}
\hline $\begin{array}{l}\text { Fig. de Gros } \\
\text { Romain }\end{array}$ & $\begin{array}{l}\text { Tiputes de St. } \\
\text { Augughis. }\end{array}$ & $\begin{array}{l}\text { Lignes de } \mathrm{Ci} \text { - } \\
\text { sero. }\end{array}$ & $\begin{array}{l}\text { Lign. de Phi- } \\
\text { loofophie. }\end{array}$ & $\begin{array}{l}\text { Lignes de Pe- } \\
\text { tit Romain. }\end{array}$ & $\begin{array}{l}\text { Iignes de Pe. } \\
\text { tit Texte. }\end{array}$ \\
\hline $27 \frac{1}{2} \ldots$ & 34. & $39 \ldots$ & $41:$ & 48 & $59 \frac{1}{8}$ \\
\hline 27 & $33 \frac{8}{4}$ & $38 \ldots$ & $40 \frac{2}{3}$ & $46 \frac{3}{4}$ & 58. \\
\hline 26 . & $32-$ & $37 \ldots$ & $39 \frac{5}{2}$ & $45 \frac{1}{2} \ldots$ & 56 \\
\hline 25 & $31 \frac{1}{2}$ & $36 \ldots$ & $38 \div$ & $44^{\frac{x}{4}} \cdot$ & 55. \\
\hline 24 & $30 \frac{x}{2}$ & $35 \ldots$ & $37 \frac{x}{3}+\cdots$ & $43 \ldots$ & 53 \\
\hline $24 \ldots$ & $29 \frac{2}{3}$ & $34 \ldots \ldots$ & $36 \div$ & $4 x^{2}$ & 52. \\
\hline
\end{tabular}

Table pour les pages In-douze.

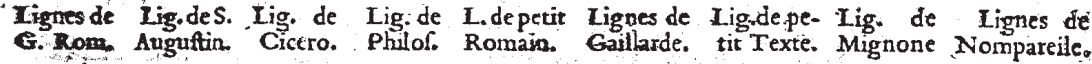
$21^{\frac{3}{4}} 27 \cdots 31 \ldots 33 \cdots 38 \ldots 42 \frac{x}{4} \cdot 47 \frac{1}{4} \ldots 61 \ldots 62$. $21 \frac{x}{4} \cdot 26 \cdot 30 \ldots 32 \ldots 36 \frac{3}{4} \cdot 41 \cdot 45 \frac{2}{3} \ldots 59 \ldots 60$. $20 \frac{1}{4}-2 x^{1}-29 \cdot 31 \cdots 35 \frac{1}{3} \cdot 39 \cdot 44 \cdots 57 \cdots 58$ $19 \frac{2}{3} \cdot 24 \frac{1}{2} \cdot 28 \ldots 29 \frac{1}{4} \cdot 34 \frac{3}{3} \cdot 38 \frac{1}{4} \cdot 42 \frac{2}{3} \cdots 55 \cdots 56$. $19 \cdot 23 \frac{\mathrm{r}}{2} \cdot 27 \cdots 28 \frac{3}{4} \cdot 33 \frac{\mathrm{r}}{4} \cdot 37 \cdots 41 \ldots 53 \cdots 54$ :

Figura 15 Una de las Tables de Fertel: cuántas líneas de cada cuerpo entran en un formato tal o cual (FERTEL, 1723, p. 5.) 
THE PRINTER's GRAMMAR. 2.7 and then, to join in the Verdict; which, we hope, will be given in our favour, after we have proved our affertion by the fubfequent Scheme.

A SCHE ME, Bewing fame of the different Sizes to which Engligh and Pica Bodies are caft.

Jam. Cant. Dutch

$\mathrm{mmmmmm}$ $\mathrm{mmmmmm}$ $\mathrm{nmmmm}$ an $m m m m$ $\mathrm{mmmmm} \mathrm{m}$ $\mathrm{mmmmmm}$ $\mathrm{mm} m \mathrm{~mm} \mathbf{m}$ $\mathrm{mm} \mathrm{mmm} \mathrm{mm}$ $\mathrm{mmmmmm}$ $\mathrm{mmmm} \mathrm{mm}$ $\mathrm{m} m \mathrm{mmm} m$ $\mathrm{mm} \mathrm{mm} \mathrm{m} \mathrm{m}$ I $2 \begin{array}{lllllll}3 & 4 & 0 & 5 & \ddot{6} & \ddot{7}\end{array}$

$$
\begin{aligned}
& \overbrace{m m m m}^{\text {mand }} \\
& m m m_{m}^{m} \\
& m m m_{m}^{m} \\
& m m m_{m}^{m} \\
& m m m_{m}^{m} \\
& m m m_{m}^{m} \\
& m m m_{m}^{m} \\
& m m m_{m}^{m} \\
& m m m_{m}^{m} \\
& m m m_{m}^{m} \\
& m m m_{m}^{m} \\
& m m m_{m}^{m} \\
& m m m m^{m} \\
& \text { I } 2345
\end{aligned}
$$

From this fketch it may be eafily gueffed, that the like variation which appears here in Englifh and Pica, prevails alfo in Founts of other Bodies. How apparent, then, is the harm and confufion which the differing in the Size of Letter of the fame Body is able to produce! and that therefore it ought to be made a law, That each of the different Bodies of Letter Thould always be caft to the SAME Height, Depth, and Line; by LetterFounders of the fame place, at leaff. But whether E 2
Jan. Cafl. Dutch

$\mathrm{m} \mathbf{m m ~ m ~ m ~ m ~}$

$\mathrm{mm} \mathrm{m} \mathrm{m} \mathrm{m} \mathrm{m}$

$\mathrm{nmmm} \mathrm{m} \mathrm{m}$



$\mathrm{m} \mathbf{m} \mathrm{mm} \mathbf{m} \mathrm{m}$

$\mathrm{mm} m \mathrm{~mm} \mathrm{~m}$

$\mathrm{mm} \mathrm{m} \mathrm{m} \mathrm{m} \mathrm{m}$

$\mathrm{m} \mathrm{mm} \mathrm{m} \mathrm{m} \mathrm{m}$

$\mathrm{m} \mathbf{m} \mathrm{m} \mathrm{m} \mathrm{m} \mathrm{m}$

$\mathrm{mm} \mathrm{m} \mathrm{m} \mathrm{m} \mathrm{m}$

$\mathrm{m} \mathrm{mm} \mathrm{m} \mathbf{m} \mathrm{m}$

$\mathrm{mm} \mathrm{m} \mathrm{m} \mathrm{m} \mathrm{m}$

I $23 \begin{array}{llllll}4 & 5 & \ddot{6} & \ddot{7}\end{array}$

Figura 16 y 17 La exposición didáctica de Smith para demostrar la diferencia entre tamaño (Size) en un "mismo" cuerpo tipográfico (Body) [SмIтH, 1755, p. 27]

Con semejante sentido de cuantificación práctica elaboró Fournier su sistema. Fournier conocía el trabajo de Truchet y se supone que lo adaptó cuando estableció su fundición de caracteres. Al pie de su Table des proportions de $1742,{ }^{21}$ exponía el procedimiento métrico del sistema: tomaba una escala de dos pulgadas (impresa a la cabeza), dividía la pulgada en doce líneas, y la línea en seis puntos. (Figura 18)

Veinte cuerpos, con su nombre tradicional, se alistaban en la tabla de menor a mayor, siguiendo la lógica cuantitativa. A la derecha, el número de lignes y points que ahora "tenían" - la ligne aún contaba como módulo. Y, entre los nombres y los números, las proportions: a partir de Petit-Romain (2 Parisiennes), cada cuerpo se descomponía en combinaciones de otros cuerpos, ya no sólo en dobles y mitades, ni sólo entre tres cuerpos ${ }^{22}$. No: ahora la proportion amplía el sentido de combinatoria, casi a lo Truchet, para exponer el conjunto tipográfico como sistema articulado. Pero la cuantificación numérica de Fournier siempre está filtrada por la materia, como una vulgarización, más grosera y comprensible para el oficio tipográfico, de aquélla: aunque buena parte de sus combinaciones parezcan discutibles en la fundición y absurdas en la composición, consideran cuerpos, no lignes ni points 




Figura 18 La Table de Fournier (1742) o el ordre parfait: un corps fixe \& une correspondance générale donde las proportions acusan la combinatoria entre cuerpos a modo de galgas

Años después, en su Manuel (1764), Fournier precisará las combinaciones y expresará todas las magnitudes en points: operatoria simplificada, sistema cumplido. Pero el famoso detalle era que su patrón métrico de base no era el oficial. ${ }^{24}$ Tal fue el "problema" del sistema de Fournier, cuya difusión efectiva continúa arrojando dudas. Lo que resulta indudable es que, de entonces en adelante, todo sistema tipométrico se articularía aritméticamente con la unidad mínima del punto, fuera éste cual fuera, legal o no.

Para muestra, Didot l'aîné — quien, hacia 1783, inauguró su fundición. Como Fournier, empezaba desde cero y podía elegir cualquier patrón métrico: eligió el pied de roi. Didot, dicen, revisó el sistema de Fournier y lo adaptó a la medida oficial -no dejó nada escrito, pero su prole se encargó de publicitarlo, disimulando el papel de Fournier. Así, Pierre Didot, en el Specimen de 1819, empezaba su relato sin pulgadas, con el cuerpo menor tradicional, la Nompareille, equivalente a una ligne de pied-de-roi, y de ahí derivaba el point, 1/6 de 
ligne, unidad operativa del sistema, pieza de espesor mínimo que se podía fundir - espacio o interlínea, no cuerpo. ${ }^{25}$

El relato del hijo de Didot también subrayaba lo inevitable: prescindir de los nombres de los cuerpos y limitarse a numerarlos. Aunque todavía se usaran en el oficio, los nombres antiguos no ofrecían idea alguna de su proporción y correlación dentro del nuevo orden numérico, le seul convenable. Así, desplaza el objetivo: el nuevo "nombre" ya no señalará usos, sino el sistema -de generación cuantitativa.

En fin, es habitual presentar la reforma de Didot como una ventaja: las medidas tipográficas se hacían compatibles con las papeleras y demás. La aceptación de Didot creció con el círculo de relaciones de su dinastía - siempre mejores que las de Fournier- y esto no debe ignorarse: es discutible que las reformas ilustradas fueran transformaciones profundas de los sistemas tipométricos en uso; es indiscutible su tránsito hacia la universalidad de la medida.

\section{La ruptura del metro}

En 1795, se oficializa en Francia el sistema métrico decimal. La diezmillonésima parte del cuadrante del meridiano terrestre reescala el sentido de naturaleza y su significación para el hombre, y favorece la articulación decimal del cómputo aritmético - por decir algo. Con su internacionalización, el sistema métrico decimal se aproxima al absoluto: como si el mundo fuera tan grande y abierto que conviniera controlar su unidad - por motivos científicos o de mercado y poder.

Así, el antiguo pied de roi y, con él, los points typographiques de Didot, devienen, en rigor, ilegales. Esto complica el siglo XIX, como reflejan sus manuales de imprenta: tablas de reducciones numéricas entre sistemas, conversiones limpias entre cuerpos de "antigua y moderna nomenclatura”, juegos aritméticos bajo el dominio del punto -con auxilio del cícero. ${ }^{26}$ (Figura 19) Y marcará el camino de cualquier intento de reforma tipométrica posterior: de un modo u otro, deberá considerar y sujetarse al sistema métrico decimal. 


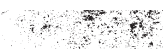 \\ GONGORDANGE \\ DU POINT TYPOGRAPHIQUE AVEG LE SYSTÈME MÉTRIQUE}

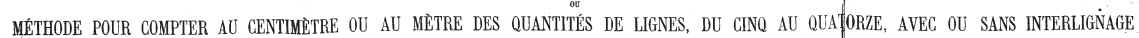

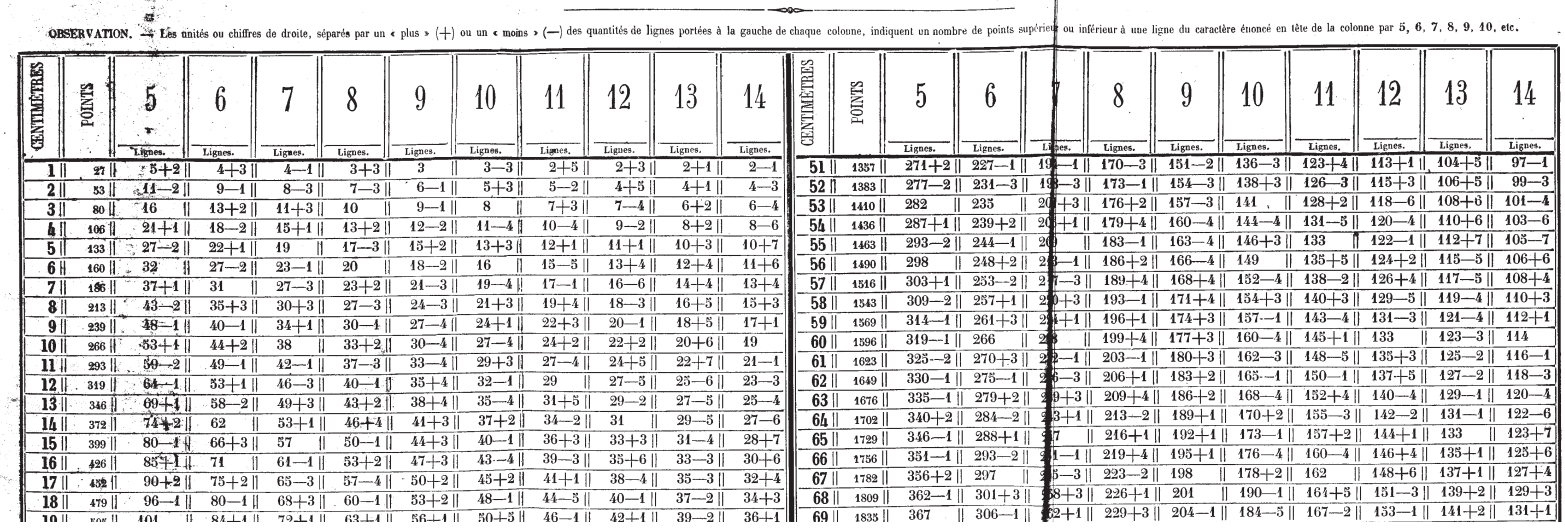

Figura 19 Un bonito ejemplo decimonónico: tablas de inmensas concordancias numéricas entre el sistema Didot y el métrico decimal. [LEFEVRE, 1855, fragmento.]

La primera tentativa fue la que el hijo de Didot l'aîné, Firmin, empezó en 1812 para la Imprimérie Imperiale, auspiciada por Napoleón, abandonada tras su caída en 1815: el point millimétrique se cifró, al parecer, en $0,4 \mathrm{~mm}-2^{1 / 2}$ points equivalían a $1 \mathrm{~mm}$. La operatoria podía resultar algo forzada, y el valor del punto "demasiado grande" respecto al de su padre (0,3759 o 0,376065 mm, según la conversión), pero nada de esto debió resultar decisivo para justificar el fracaso de su avance.

No se expondrán más intentos ${ }^{27}$ — que cuestionarían su propio valor o abonarían el arraigo material a los sistemas anteriores. Y es que, a partir de aquí, todo puede sucederse tan deprisa como sea, pero, en el fondo, el sustrato conceptual se mantiene, se acumula, y sólo se refina. Esto vale tanto para el Point system angloamericano, como para los sistemas de composición en caliente, en frío y, con reservas, el entorno digital: el problema se desplaza al punto -cuánto mide y por qué no hay un punto para todos. ${ }^{28}$

Así, terminamos con las Meterkonkordanz de Berthold, hacia 1878: no una reforma estricta, sino un esquema de equivalencias entre sistemas métricos. Hermann Berthold, industrial berlinés, fue encargado por los fundidores alemanes para "concordar" el sistema tipométrico que éstos adoptaron, el ya ilegal Didot, con el sistema métrico decimal, de uso oficial en el proceso de unificación de Alemania. El resultado: $1 \mathrm{~m}=2660$ $\mathrm{p} ; 30 \mathrm{~cm}=798 \mathrm{p} ; 1 \mathrm{p}=0,3759 \mathrm{~mm} \cdot{ }^{29}$ La lógica científica obligaba a llenar un metro con puntos. La lógica tipográfica, a distribuir tipómetros de 30 cm entre fundidores: una medida ternaria incómoda en el metro, pero, en términos de uso, asimilable al pie o al folio -ahora casi un DIN A4. Y, en el fondo, eso: los puntos son, como mínimo, décimas de milímetro; como mucho, menos que milésimas de milímetro - háganse operaciones con las cifras proporcionadas, no van a coincidir. Éste es un "nuevo" modo de entender las unidades tipográficas, donde la precisión lleva, en última instancia, a la aproximación. 
El baile de números es distinto en el entorno del uso y del proyecto gráfico, donde los valores "reales" se redondean a efectos de cálculo -así, en el "tipómetro Berthold". (Figuras 20 y 21) Regla finamente rayada, transparente por lo general, se fundamenta en la concordancia (aproximada) de 48 puntos Didot $=18 \mathrm{~mm}$. Toda medida modulada en cuerpo 48 concordará con el sistema métrico decimal. Si 48 es un cuerpo tipográfico canónico, 18 milímetros son algo extraños en la articulación decimal del metro. Pero al lado de las concordancias estrictas con el sistema métrico decimal, hay las concordancias internas del sistema tipográfico.

Desde éste, las Meterkonkordanz restablecen una relación métrica perdida, una medida que conjunta las relaciones modulares del material tipográfico, bajo la tutela del cálculo. El conjunto de cuerpos se puede reconsiderar desde el patrón de 48 puntos: un área divisible por 48 siempre será divisible por algún otro cuerpo en la escala tipométrica o, lo que es igual, el área se puede dimensionar por distintos módulos. Y, aunque estos módulos remitan a cuerpos numéricos, su articulación es la tradicional de cuadratines, en superficie.
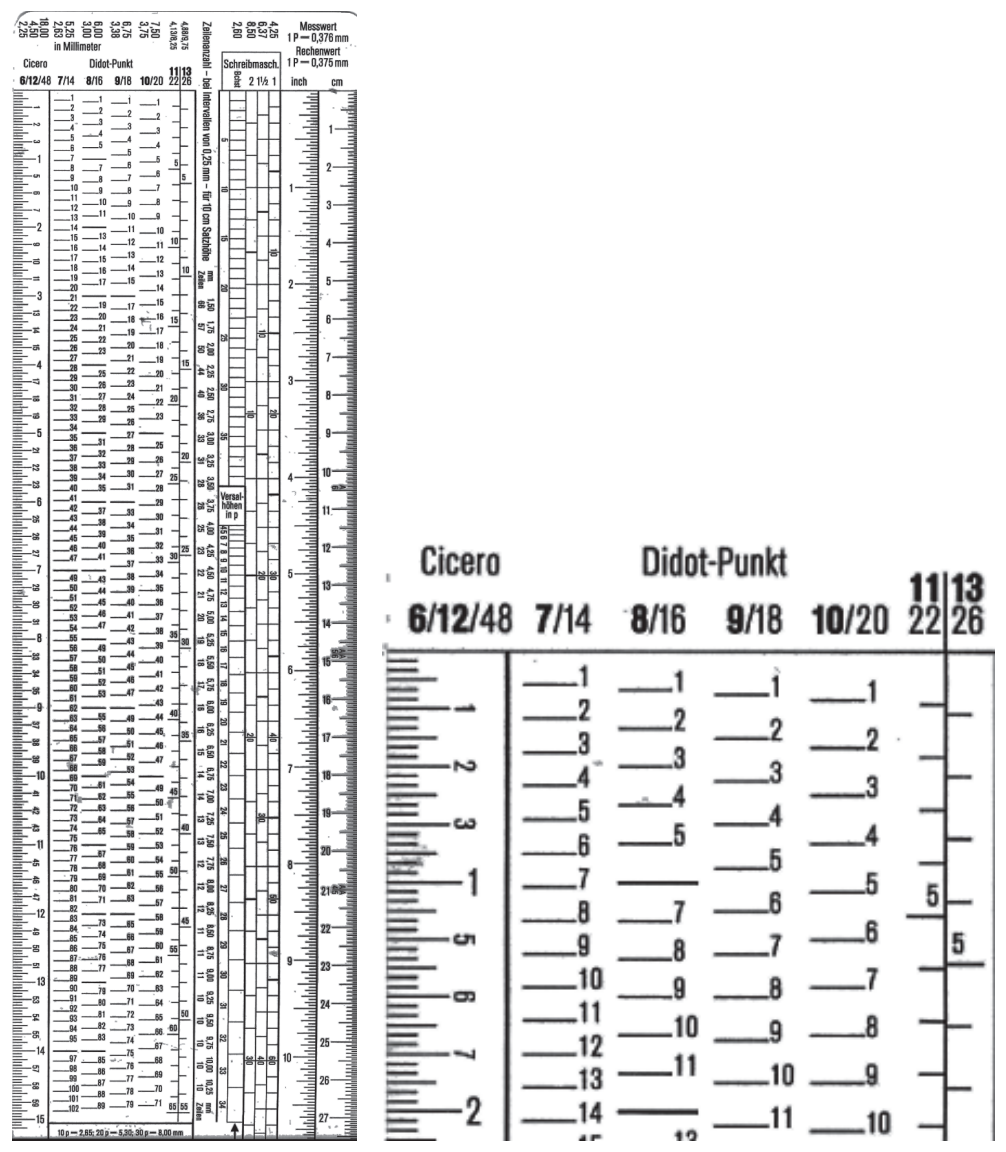

Figura 20 y 21 El tipómetro "de Berthold” habitual: transparente y repleto de rayitas. La concordancia básica ( 48 puntos Didot $=18$ milímetros) se evidencia en las escalas de cuerpos del tipómetro: en la del 48 , con cifras que lo presentan como módulo; en el resto, con una línea sin numerar, que remite a la escala base 


\section{Después del plomo}

Tras el lapso aritmético, la métrica tipográfica acusará un rumbo ingenieril..$^{30}$ En el tránsito de composición en caliente, la monotipia


espacios-cuña para resolver aún la medida —-daría igual el sistema métrico: la máquina es un sistema. Aquí ya asoma la precisión métrica que fragmenta las unidades en millonésimas, fracciones que sólo se pueden leer -medidas que han dejado de ser manejables, luego son insensibles. Lógico, porque cada vez habrá menos por tocar: con el desapego de la materia, la medida, y sus valores, mudarán de sentido - con algún que otro recuerdo, como Cícero y Pica, únicos módulos nominales.

Esto sucederá en la composición en frío y electrónica, donde lo más perceptible es su inmaterialidad, que cuestiona el cuerpo hasta el punto de debatir qué medir, en una letra. ${ }^{31}$ No es extraño entonces que nos desorientemos en la medida ultrarelativa de la pantalla: ampliar y reducir, elegir unidades (puntos, píxeles, porcentajes... sistemas métricos locales encapsulados en una caja), decidir equivalencias, ignorar o subvertir los referentes métricos establecidos -se nos permite creer que imponemos nuestras reglas para volver a tener un sistema a medida.

Tal vez en todos estos años no hayamos cambiado tanto: que nuestras pulgadas sean semejantes, que tengamos los ojos tan equidistantes como entonces, para leer líneas de igual medida. Tal vez, y no debe chocar que dispositivos electrónicos se llamaran palm y que, en su interior, las letras parezcan no tener mesura. Esto preocupa a algunos: que varíen su medida. Pero sólo parece lógico: tras desprenderse del cuerpo, la letra debe animarse -y seguramente no es cuestión de medirla según patrones pasados. Esto se nos escapa aquí, otros deberán llenar el hueco. 


\section{Notas}

1 Por comodidad, se omiten las medidas de superficie y de capacidad, derivaciones de las longitudinales; las más abstractas de peso, tiempo, o moneda; y otros aspectos métricos, como los valores morales -posiblemente implícitos, difícilmente mensurables.

2 El uso básico de la medida se resuelve menos en clave de armonía que de aproximación concreta. En el argumento presente, es irrelevante distinguir entre la medida antropológica originaria, y su equivalente en patrón métrico.

3 Dicha inversión procede del principio de molde, a tres niveles: molde de fundición, matriz, tipo movible. La producción tipográfica encadena las piezas y sus grafismos en secuencia alterna: contrapunzón-punzón-matriz-tipo-impreso. Al inicio del proceso, el punzonista arma las letras a partir de su contragrafismo o blanco interno (por ejemplo, el óvalo de la o).

4 El cuerpo tipográfico es la distancia entre las caras anterior y posterior del tipo movible o pieza física: en él queda contenido el ojo de la letra, o grafismo impresor. Por definición, el ojo es menor al cuerpo: como todo molde, el tipo movible necesita un mínimo de conicidad para poder extraerse de la matriz. El cuerpo se denominó "grueso", "grado" y, ocasionalmente en el siglo XIX, "fuerza de cuerpo". En el siglo XX, la denominación usual fue "cuerpo" -aunque, tras los sistemas de fotocomposición, conviniera "tamaño". En todo caso, cabe destacar que el cuerpo en un impreso es un recuerdo distorsionado del cuerpo físico: el papel, que se encoge y dilata, no ayuda.

5 En cuerpos grandes, los cuadrados son menores en número por motivos de producción. Así, en la tradición del XIX-XX, los cuadrados del 48 sólo son de 1 11/2 y 2 cuadratines.

6 Los nombres y las proporciones pueden variar ligeramente según tiempo y lugar: en el siglo xx español, la serie de espacios se redujo a grueso, mediano y fino -éste, invariablemente de 1 punto (cf. MORATO, 1900, p. 364).

7 El argumento toma como base las definiciones que Sigüenza ofrece en la "Adicion al Mecanismo".

8 Y de intercambio: conceptualmente, los blancos son "de cuerpo", se usan en cualquier alfabeto de tal cuerpo - pero una misma pieza puede usarse en distintos cuerpos: medio cuadratín del 24 es un cuadrado de dos cuadratines del 12.

9 (Item ocho cajones de madera con diversas cajas, provistas de letras de estampa, esto es, letra gorda, y letra mediana, y letra de glosar, y letra menuda.) Rubió, 1955: 455, extracto del Doc. 251.

10 Todas estas letras de Posa son "góticas", pero esto no rebaja la importancia de la calificación métrica para definirlas. Sus equivalencias aproximadas en puntos tipográficos: 18, 14, 12, 10.

11 La relación entre grados y formatos llena páginas en los manuales de imprenta, ya desde sus inicios: su estudio comparado permite trazar la evolución y fluctuaciones de las "franjas tipográficas".

12 La lista presenta una visión panorámica que no puede ser exhaustiva ni completa. Se enumeran los grados de mayor a menor, de uso más o menos común en el área española: separados por guiones, los grados de otras áreas geográficas; entre paréntesis, los de dudosa adscripción -respetando en lo posible las grafías particulares de origen. Es habitual en los tratados (Caramuel (1664) o Paredes (1680?) sirven como ejemplos tempranos) dedicar líneas a contar la procedencia de los nombres, acertada o no. 
13 Los cuantitativos no constan en el panorama español hasta el XIX, cuando se multiplican. El doble sería algo como las "letras de dos puntos" (titulares mayúsculas), pero con minúsculas. Las duplicaciones son las únicas relaciones que acostumbran a exponerse: Grancanon = 2 Parangona; Peticano $=2$ Atanasia; Parangona $=2$ Breviario; Texto $=2$ Glossa $($ Paredes, 1680?: 6v-8r $)$.

14 Canon, Parangona y Nomparella, son las únicas denominaciones de grados tipográficos que se mantienen, a lo largo del tiempo, en todas las áreas geográficas (con la ilustre excepción de Moxon (1683-4), que no cita Paragon). El repaso distingue este subconjunto métrico por su consistencia y relevancia en el entorno peninsular aunque su papel se vería menguado por los grados más aparentes y operativos en términos de uso y de percepción: el Cícero y la Pica.

15 Un tópico es que Canon se nombró así porque "este" grado se usaba para el canon de la misa. Ya es suficiente: constituye un uso tipográfico "limítrofe", una magnitud-límite.

16 Se juega con un Canon genérico, algo imaginario: es el grado tipográfico al que se aplicaron más calificaciones y, así, sería una franja por propio derecho. En el cuadro tradicional, casi todos los cuerpos mayores que Parangona son Canon -su número varía entre dos y cinco. La "serie básica", sin embargo, es Gran-Canon y Petit-Canon; Canon, sin calificar, es menos habitual. Desde las equivalencias a puntos tipográficos, Peticano puede ser de 24 a 28; y Grancánon, de 44 a 48. Lo más usual sería tomar un Canon que contuviera 2 Parangona. La Parangona puede equivaler a 18 puntos, y la Nomparella a 6 puntos: en una Parangona caben 3 Nomparella.

17 El papel de la Parangona es destacado por Sigüenza (1811, p. 17), recordando al "professor Ibarra", quien "tomaba todas las medidas del ancho de la plana á emes justas de parangona". Que eso constituya "el sistema español antiguo", como apunta Serra i Oliveres (1852, p. 272-3), es cuestionable - pero puede concederse que fuera, en palabras del mismo autor, una "costumbre española".

18 "And that the Reader may the better understand the sizes of these several Bodies, I shall give him this Table following; wherein is set down the number of each Body that is contained in one Foot. Pearl, 184 | Nomparel, 150 | Brevier, 112 | Long-Primmer, 92 | Pica, 75 | English, 66 | Great-Primmer, 50 | Double-Pica, 38 | Two-Lin'd English, 33 | Great-Cannon. 171/2 $\}$ contained in one Foot." (Moxon, 1683-4 (1962), p. 21)

19 El Romain du Roi, algo más que el alfabeto corporativo de Louis XIV, fue proyectado por un grupo asociado a la Académie Royale des Sciences (Truchet, Jaugeon, Des Billettes, bajo la tutela del abbé Bignon). El programa métrico en debate aquí se inscribe en un marco más amplio que el tipográfico.

20 Pero no se menciona el point. Contra la lógica duodecimal ( 1 línea = 12 puntos), algunas fuentes contemporáneas subdividen la ligne en 6, 8 o 10: cf. Mosley en su edición del Manuel de Fournier (1995, vol. 3: 351-2). Las equivalencias pulcras dicen que 2 lignes secondes son 1 punto Didot.

21 Según refiere Fournier en el primer volumen del Manuel (1764: 130-2), la Table donde presentó su “invención" es de 1737: los estudiosos dan crédito a esta fecha, consideran perdido el impreso.

22 Ya se ha aludido a la exposición por dobles de Paredes (1680?). En Fertel (1723: 1-3), o el Réglement de la Libraire de 1723, aparecen expresiones como "Le Petit Romain = Une Nompareille \& une Parisienne": en tales proportions nunca intervienen más de tres cuerpos.

23 No en vano su Prototype de 240 points typographiques ou 20 cicéros, un recipiente para comprobar los cuerpos, se puede tomar como antecesor del tipómetro. 20 cíceros es una medida próxima a la palma, habitual para libros manejables. 
24 Como anotó en su Table de 1742, 11²/2 lignes suyas equivalían a 10¹/2 lignes géometriques.

25 El mismo Specimen ofrece las fastidiosas muestras de cuerpos intermedios o demi-points: $81 / 2$, etc. - un refinamiento que remite a la subdivisión duodecimal de la ligne y complica las existencias alegando plus de richesse.

26 El caso extremo es Serra i Oliveres (1852, p. 171-5) quien lo mide todo en puntos: no sólo los cuerpos, también las imposiciones y los formatos de papel. En la segunda mitad del XIX, por influencia francesa y alemana, se generalizará en España el uso del Cícero (12 puntos) sobre el tradicional Lectura.

27 Tracy (1961), Tormo Freixas (1973) y Boag (1996) ofrecen algunos ejemplos en sus artículos.

28 El Point System recorrió un camino inverso al de Fournier y Didot. La fundición Marder, Luse \& Co. de Chicago también empezaba desde cero en 1872, tras el incendio del año anterior: calibró su material ajustando seis picas en una pulgada, su punto ("Chicago point") igual a 1/72 de pulgada. En 1886, la United States Typefounders' Association adoptó aquel sistema de puntos, pero no el valor de su pica: se impuso la de MacKellar, Smiths \& Jordan de Philadelphia, por prestigio. Casi un siglo más tarde, en 1984, el PostScript de Adobe ( $y$, así, Apple) recuperará el "Chicago point". Los valores de punto en milímetros que ofrece Boag (1996): angloamericano, 0,3514598; DTP, 0,3527785; en contraste con los de Fournier $(0,35)$ y Didot $(0,376065)$.

29 Para más “equivalencias”, v. Smalian (1899).

30 Un retrato característico puede ser Typographical Printing-Surfaces (1916), de Legros y Grant: la precisión del ingeniero complementa el catálogo de maquinaria moderna.

31 El debate puede afinar la misma noción de “tipometría” y situarla en la creación tipográfica.

\section{Referencias}

Tipografía. Fuentes fundamentales: manuales

CARAMUEL, Juan. Syntagma de Arte Typographica. [1664] Edición, traducción y glosa de Pablo Andrés Escapa. ?: Instituto de Historia del Libro y de la Lectura; Fundación Duques de Soria; Fundación Germán Sánchez Ruipérez, 2004. FERTEL, Martin-Dominique. La science pratique de l'imprimerie. Saint-Omer: Martin-Dominique Fertel, 1723.

FOURNIER, Pierre-Simon. Manuel typographique, 1764-1766. Facsimile edition, 3 vols., Darmstadt, 1995 (vol. 3 includes a facsimile reprint of Carter, Fournier on typefounding, 1930), edited by James Mosley. [Paris: Barbou, 1764-1766]

LEFEVRE, Théotiste. Guide pratique du compositeur d'imprimerie. Paris: Firmin Didot frères, 1855. 
LEgros, Lucien Alphonse; Grant, John Cameron. Typographical Printing-Surfaces. The Technology and Mechanism of their Production. London, New York, Bombay, Calcutta, and Madras: Longmans, Green, and Co.,1916. [Ed. facsímil. New York; London: Garland Publishing, Inc., 1980.]

MORATo, Juan José. Guía práctica del compositor tipográfico. Madrid: Hernando y Compañía, 1900.

Moxon, Joseph. Mechanick Exercises on The Whole Art of Printing (1683-4). London: Oxford University Press, 1962 [1a ed. 1958].

PAREDES, Alonso Víctor de. Institución y origen del arte de la imprenta y reglas generales para los componedores [1680?] Edición y prólogo de Jaime Moll. Nueva noticia editorial de Víctor Infantes. Madrid: Calambur, 2002.

SERRA y OLIVEREs, Antonio. Manual de la tipografía española, ó sea el arte de la imprenta. Madrid: Librería de D. Eduardo Oliveres, 1852.

SIGÜENZA Y VERA, Juan Joseph. Mecanismo del arte de la imprenta para facilidad de los operarios que le exerzan (1811). [Edición facsímil. Madrid: Almarabu, 1992.]

SIGÜENZA Y VERA, Juan Joseph. Mecanismo del arte de la imprenta para facilidad de los operarios que le exerzan. Segunda edicion aumentada. [Incluye "Adicion al mecanismo del arte de la imprenta para inteligencia de los operarios que le profesan", con los "Nombres técnicos pertenecientes á este arte”.] Madrid: Imprenta de la Compañía, 1822.

SмIтн, John. The Printer's Grammar (1755). [Ed. facsímil. English Bibliographical Sources, Series 3: Printer's Manuals, n. 2. London: Gregg Press Ltd, 1965.]

Tipografía. Fuentes fundamentales: estudios

BOAG, Andrew. "Typographic measurement: a chronology". Typography papers, 1, 1996, pp. 105-121.

DREYFUS, John (ed.). Type Specimen Facsimiles. Reproductions of Fifteen Type Specimen Sheets issued between the Sixteenth and Eighteenth Centuries. Accompanied by notes mainly derived from the researches of A.F. Johnson, Harry Carter, Matthew Carter, Netty Hoeflake, Mike Parker. General editor John Dreyfus. With an introductory essay by Stanley Morison. London: Bowes \& Bowes; Putnam, 1963.

DREYFus, John (ed.). Type Specimen Facsimiles II. Reproductions of Christopher Plantin's Index Sive Specimen Characterum 1567 \& Folio Specimen of c. 1585, together with the Le Bé - Moretus Specimen c. 1599. With annotations by Hendrik D. L. Vervliet and Harry Carter. London: The Bodley Head, 1972. MADURELl MARIMón, J.M.; Rubió Balaguer, J. Documentos para la historia de la imprenta y librería en Barcelona (1474-1553). Barcelona: Gremios de Editores, de Libreros y de Maestros Impresores, 1955.

MOSLEY, James. "French academicians and modern typography: designing new types in the 1690s". Typography papers, 2, 1997, pp. 5-29.

Smalian, Hermann. "Type Systems of To-day". The British Printer, XII, 1899, pp. 65-66 [BP, XII (1899), n. 68 (March-April)]; 130-131[BP, XII (1899), n. 69 (May-June)]; 181-182 [BP, XII (1899), n. 70 (July-August)]; 239-241 [BP, XII (1899), n. 71 (September-October)].

Steinberg, s. H. Five Hundred Years of Printing. Harmondsworth: Penguin, 1955. TORMO FREIXAs, Enric. “Un tema candente. La ilegalidad del cícero”. Gremio de 
Industrias Gráficas de Barcelona, Junio 1973.

TrACY, Walter. “The point”. Penrose, 55, 1961.

Metrología histórica y afines

ALsinA, Claudi; Feliu, Gaspar; Marquet, Lluís. Diccionari de mesures catalanes. Barcelona: Curial, 1996.

KULA, Witold. Las medidas y los hombres. Madrid, México: Siglo XXI, 1980.

\section{Sobre el autor}

\section{Oriol Moret Viñals}

< oriolmoret@ub.edu>

Barcelona, 1968. Doctor en Bellas Artes por la Universitat de Barcelona con una tesis sobre tipometría, más o menos. Profesor Lector de la Facultad de Bellas Artes de la misma universidad. Docente desde 1991 en escuelas locales de diseño, combinó la docencia con la ilustración y la maquetación hasta 2012. Docente en el Departamento de Diseño e Imagen de la Facultad de Bellas Artes de la Universidad de Barcelona desde 1997: en licenciatura y diversos cursos de postgrado (19972001) (2004-2012) (2008-2012), coordinador del taller de tipografía y asignaturas asociadas e integrante del grupo de investigación en Tipografía con proyectos financiados (1998-2004).

Artigo recebido em 25 abr. 2014, aprovado em 20 ago. 2014. 